Revista de Derecho

de la Pontificia Universidad Católica de Valparaíso

51 (segundo semestre de 2018)

[pp. 199 - 230]

\title{
LA PROPIEDAD EN CHILE Y SUS DILEMAS
}

[Property in Chile and its dilemmas]

\author{
Pablo Ruiz-Tagle* \\ Universidad de Chile
}

Resumen

Este trabajo postula como hipótesis que la propiedad privada a nivel constitucional en Chile no tiene un concepto único, sino que tiene forma de dilemas y carácter multiforme. Para comprobar o refutar dicha hipótesis se aplica el método dogmático jurídico al material normativo asociado a la costumbre, la doctrina y la jurisprudencia como fuentes del Derecho Constitucional chileno, separando los dilemas de la propiedad chilena presentes en los registros de los encuentros locales autoconvocados llevados a cabo por la ciudadanía, en la doctrina de los juristas constitucionalistas chilenos y en la jurisprudencia del Tribunal Constitucional chileno. Como conclusión, se comprueba la hipótesis planteada, constatando que las ideas de la ciudadanía chilena agregan elementos nuevos a la propiedad privada a nivel constitucional en Chile, tales como los vínculos entre este derecho y el derecho a la vivienda, un derecho a asegurar un mínimo de propiedad a todas las personas y la protección de algunas formas de propiedad indígena. Adicionalmente, se concluye que existen discrepancias muy acentuadas en la doctrina y en la jurisprudencia sobre propiedad privada a nivel constitucional en Chile.

Recibido el 25 de octubre de 2018 y Aprobado el 6 de diciembre de 2018

* Profesor Titular de Derecho Constitucional y de Introducción al Derecho de la Facultad de Derecho Universidad de Chile. Máster y Doctor en Derecho, Universidad de Yale. Este artículo se vincula con el proyecto regular FONDECYT N. ${ }^{\circ} 1120830$, cuyo apoyo y financiamiento cumplo con agradecer. En la edición de este trabajo, agradezco las sugerencias del ayudante Joaquín Deck Labra. 


Palabras ClaVE
Propiedad - dilema jurídico
constitucional - doctrina -
jurisprudencia - ciudadanía - Derecho
constitucional.

Palabras clave

I. INTRODUCCIÓN

Los juristas y abogados en ejercicio de la profesión en Chile tienden a reconocer la existencia de un único concepto de propiedad privada a nivel constitucional, lo que podría explicarse por la forma en que ésta es consagrada en el texto positivo de la Constitución vigente en Chile (también referida como C. Pol.) $)^{1}$.

En contraste, la hipótesis de este trabajo es que la propiedad privada a nivel constitucional en Chile tiene forma de dilemas ${ }^{2}$ y carácter multiforme $e^{3}$, como se aprecia en los encuentros locales autoconvocados de la ciudadanía, en la doctrina constitucional chilena y en la jurisprudencia del Tribunal Constitucional chileno (en adelante denominado TC).

Para comprobar o refutar esta hipótesis aplicaré el método dogmático jurídico. El objeto sobre el cual aplicaré dicho método será un conjunto de materiales normativos que pueden asociarse a ciertas fuentes del Derecho Constitucional chileno: costumbre ${ }^{4}$, doctrina y jurisprudencia. Dichas

\footnotetext{
${ }^{1}$ Sin perjuicio de ello, la Constitución vigente en Chile establece distintos tipos de propiedad privada, entre las cuales se encuentran, por ejemplo, la propiedad minera y la propiedad intelectual.

${ }^{2}$ Real Academia Española, Diccionario (23o edición, Madrid, Real Academia Española, 2014), p. 1000, define la palabra dilema en dos acepciones diferentes:

"1. m. Situación en la que es necesario elegir entre dos opciones igualmente buenas o malas.

2. m. Fil. Argumento formado por dos proposiciones contrarias disyuntivamente, de tal manera que, ne-gada o concedida cualquiera de las dos, queda demostrada una determinada conclusión”.

${ }^{3}$ Esta idea de un derecho de propiedad multiforme que entra en conflicto con otros derechos y con intereses colectivos es objeto de un profundo estudio en Underkuffler, Laura, The idea of Property: Its meaning and power (Oxford, Oxford University Press 2003).

${ }^{4}$ Para efectos de este trabajo, se adoptará como supuesto explícito que los registros de los distintos encuentros locales autoconvocados llevados a cabo por la ciudadanía en Chile son materiales normativos constitutivos de costumbre como fuente del Derecho Constitucional chileno. Para una explicación de la costumbre como fuente del Derecho chileno, especialmente en Derecho Público, nos remitimos a lo explicado por los profesores Renato Cristi y Pablo Ruiz-Tagle, en su libro "La República en Chile. Teoría y práctica del Constitucionalismo Republicano".
} 
fuentes se seleccionan como una muestra no exhaustiva ${ }^{5}$, más para iniciar la discusión que para agotarla de entrada.

La estructura de este trabajo se alinea con el objetivo de confirmar o refutar la hipótesis planteada, por lo que se examinarán en primer lugar los dilemas presentes en el concepto de propiedad privada de la ciudadanía, el más novedoso y desconocido para los juristas y abogados en ejercicio de la profesión en Chile. Acto seguido, se examinarán en segundo y tercer lugar los dilemas presentes en los conceptos de propiedad privada de los constitucionalistas chilenos y del TC, respectivamente. Por último, se presentarán las conclusiones de este trabajo.

\section{Dilemas DE LA PROPIEDAD CHILENA EN LA CIUDADANÍA}

El día 14 de octubre de 2015, la Presidenta Michelle Bachelet convocó a un Consejo de Observadores a coordinar y fiscalizar un proceso de deliberación ciudadana en diálogos y cabildos abiertos a toda la ciudadanía para expresar sus ideas constitucionales en encuentros locales autoconvocados, en adelante denominados ELA ${ }^{6}$. Los resultados de esta participación ciudadana en lo que se refiere al derecho de propiedad en general coinciden con las propuestas de doctrina y jurisprudencia constitucional que explicaremos en este trabajo. Sin embargo, hay algunas propuestas ciudadanas que constituyen manifestaciones alternativas y que agregan un nuevo dilema a la comprensión de la propiedad en Chile. Una muestra de estas ideas se expone a continuación ${ }^{7}$.

Véase Cristi, Renato - Ruiz-Tagle, Pablo, La República en Chile. Teoría y práctica del Constitucionalismo Republicano (Santiago, LOM Ediciones, 2006), pp. 112-114.

${ }^{5} \mathrm{Si}$ bien la ley es considerada la principal fuente del Derecho chileno, es por esa misma razón la más tratada con el método dogmático jurídico. Por ello, en lo relativo a la propiedad privada a nivel constitucional en Chile, nos remitimos a lo explicado por el Profesor Daniel Peñailillo en su libro titulado "Los Bienes". Véase Peñailillo, Daniel, Los Bienes (Santiago, Editorial Jurídica de Chile, 2006).

${ }^{6}$ Soto, Francisco - Welp, Janina, Los "diálogos" ciudadanos. Chile ante el giro deliberativo (Santiago, LOM Ediciones, 2017), pp. 165-173 y Ruzz-Tagle Vial, Pablo, Propiedad Intelectual y Contratos (Santiago, Editorial Jurídica de Chile, 2001), pp. 278281.

${ }^{7}$ Resultados de Encuentros Locales; disponibles [en línea]: http://datos.gob.cl/ dataset/proceso-constituyente-abierto-a-la-ciudadania/resource/85d1b1ac088b-4ee6-b545-6f9435f6fe5c; y vhttp://datos.gob.cl.s3.amazonaws.com/ Resultado_Encuentro_Local_Memoria_Historica.xlsx (consultado por última vez el 23 de febrero de 2018). Aparecen en una planilla Excel sin página y que en este trabajo son denominadas Datos, junto con la mención del número de celda respectivo. 
En los documentos con los resultados de los ELA, consta que el derecho de propiedad fue considerado en un nivel medio de referencia ciudadana en cuanto a los demás derechos. Por encima del derecho de propiedad hay en los ELA referencias al derecho a la educación, el derecho a la igualdad ante la ley, el derecho a la participación, el derecho a la salud, el derecho a la seguridad social, al derecho a la vida sin violencia, el derecho la vivienda digna, el derecho a la no discriminación, el derecho a sindicalizarse y a la negociación colectiva, el derecho al sufragio, el derecho a respetar la naturaleza y medio ambiente, el derecho al trabajo, el derecho de los pueblos indígenas, los derechos de los niños, niñas y adolescentes. El derecho de propiedad se sitúa en un nivel de menciones semejante a la libertad personal, el derecho a la protección judicial de los derechos, el derecho de acceso de identidad cultural y el derecho a la cultura, el derecho a la información, el derecho a la libertad de conciencia y el derecho a la libertad de enseñanza. Las menciones al derecho de propiedad se sitúan por encima de las menciones al derecho de igualdad ante los tributos, el derecho a la honra, el derecho a la libertad ambulatoria, el derecho a la nacionalidad, el derecho a la privacidad e intimidad, el derecho de asociación y el derecho de petición a las autoridades. A este respecto podemos afirmar que menciones al derecho de propiedad muestran que la ciudadanía tiene una satisfacción relativa o media con la forma en que la Constitución vigente en Chile regula este derecho. En uno de los ELA, se sitúo expresamente al derecho de propiedad en el séptimo lugar de importancia o preferencia entre los temas de derechos ${ }^{8}$, sin perjuicio de que algunos grupos le asignaron la primera prioridad. ${ }^{9}$. La ausencia de mención a un derecho en los ELA no significa falta de interés por el mismo, sino que también puede entenderse como una satisfacción ciudadana con la forma en que la Constitución vigente en Chile regula ese derecho en particular.

El profesor Bruce Ackerman ha estudiado el contraste entre las concepciones de la propiedad de las personas comunes, esto es, del tipo ideal de ciudadano ordinario, por una parte, y la de especialistas dedicados en forma comprensiva y científica a las políticas públicas, por otra parte ${ }^{10}$. Al parecer, en el estudio de los resultados de los ELA realizados en Chile no se da la clase de contraste que advierte Ackerman. Muchos de los resultados de los ELA coinciden con la concepción de la jurisprudencia diversificada de la propiedad que acepta que este derecho está sometido a reglamentación en forma flexible, y expresó que la propiedad que admite diversas formas, tales

\footnotetext{
${ }^{8}$ Datos, cit. (n. 7), 103954.

${ }^{9}$ Datos, cit. (n. 7), 175875.

${ }^{10}$ Ackerman, Bruce, Private Property and the Constitution (New Haven and London, Yale University Press, 1977), pp.10-20.
} 
como propiedad social, cooperativa, cultural, patrimonial, artesanal, individual, comunitaria etc. ${ }^{11}$; y se percibe como un derecho que no debe estar por encima del derecho a la vida, ni por encima del bien común ${ }^{12}$. Además, se vincula con la idea de la protección de los derechos adquiridos ${ }^{13}$ y con la propiedad estatal de recursos básicos y estratégicos ${ }^{14} \mathrm{e}$, incluso, con la idea de nacionalizar algunos recursos naturales ${ }^{15}$. También se propuso la idea de imponer royalties y plazos en la propiedad de la minería ${ }^{16}$, y se reitera la idea de que la propiedad debe fundarse en el trabajo o esfuerzo humano ${ }^{17}$, y/o que ella está referida a una idea de propiedad social ${ }^{18}$. En los ELA hay muchas referencias a la función social de la propiedad y a sus limitaciones, tales como garantizar el acceso de playas, parques, plazas, cerros, conservación de la naturaleza, etc. ${ }^{19}$. En forma recurrente también se percibe la necesidad de proteger la propiedad estatal o la propiedad sobre los recursos naturales como una tarea preferente del Estado ${ }^{20}$. Se ha pensado también que la propiedad no es un derecho absoluto, sino que guarda relación y es garantía de otros derechos o de valores como la solidaridad o dignidad ${ }^{21}$. Algunas personas han propuesto que la propiedad sobre el agua no debe ser privada o la consideran como bien nacional de uso público ${ }^{22}$.

Por otra parte, en abono de la concepción de propiedad unificada y reforzada que impone requisitos estrictos sobre la reglamentación, la ciudadanía ha reclamado la protección de la propiedad corporal e incorporal y en sus diversas especies ${ }^{23}$. También hay ciudadanos que expresaron su crítica a las regulaciones excesivas que se imponen sobre el ejercicio del derecho de propiedad, que constituyen verdaderas expropiaciones regulatoria ${ }^{24}$. Hay vinculación de la propiedad con el trabajo intelectual, la creatividad, la propiedad intelectual y los derechos de autor ${ }^{25}$. La propiedad es percibida por la ciudadanía como una protección para que el Estado no abuse de los

\footnotetext{
${ }^{11}$ Datos, cit. (n. 7), 211352, 212021,215362.

${ }^{12}$ Datos, cit. (n. 7), 151362.

${ }^{13}$ Datos, cit. (n. 7),150887.

${ }^{14}$ Datos, cit. (n. 7), 24961.

${ }^{15}$ Datos, cit. (n. 7), 26260.

${ }^{16}$ Datos, cit. (n. 7), 177736.

${ }^{17}$ Datos, cit. (n. 7),189723.

${ }^{18}$ Datos, cit. (n. 7), 204526.

${ }^{19}$ Datos, cit. (n. 7), 973,196479 y 198525.

${ }^{20}$ Datos, cit. (n. 7), 2759 y 216401.

${ }^{21}$ Datos, cit. (n. 7), 82244.

${ }^{22}$ Datos, cit. (n. 7), 2852, 193474 y 193661.

${ }^{23}$ Datos, cit. (n. 7),192892.

${ }^{24}$ Datos, cit. (n. 7), 151362 y 175079.

${ }^{25}$ Datos, cit. (n. 7), 185801.
} 
ciudadanos o no imponga conductas arbitrarias ${ }^{26}$. Se ha expresado que toda afectación de la propiedad siempre debe indemnizarse ${ }^{27}$, y que la privación de un bien debe estar justificado en la ley, ${ }^{28}$ que sólo es aceptable en casos excepcionales y con justa compensación ${ }^{29}$. Se considera la propiedad como garantía de desarrollo de las personas o de la personalidad ${ }^{30}$, como base de nuestro sistema económico ${ }^{31} \mathrm{y}$ como algo ligado a la idea de certeza jurídica y Estado de Derecho ${ }^{32}$. También se expresó la necesidad de mantener el vínculo entre el derecho de propiedad y el derecho de herencia ${ }^{33}$.

En una forma alternativa a las concepciones jurisprudenciales y doctrinarias que utilizaremos en este trabajo y que denominamos diversificada y unificada, respectivamente, la ciudadanía en forma original ha vinculado la propiedad con el acceso a la vivienda, lo que puede significar incluir este derecho fundamental en forma no autónoma, sino como parte del derecho de propiedad ${ }^{34}$. Otras personas han pedido agregar la idea de que todas las personas tienen derecho a poseer un bien y su propiedad o a tener protección de sus bienes personales, lo que refleja una idea de un mínimo de propiedad cercana al principio del artículo 19 número 23 de la Constitución vigente en Chile ${ }^{35}$. Del mismo modo, la idea ciudadana en los ELA considera la propiedad un derecho humano $y / o$ fundamental ${ }^{36}$, que es necesario para el desarrollo individual y colectivo y que está íntimamente ligada al bienestar, las expectativas de vida y el desarrollo de los regímenes democráticos ${ }^{37}$. Los ciudadanos finalmente plantearon que se debe garantizar el derecho de propiedad de las comunidades indígenas ${ }^{38}$, y asegurar sus conocimientos $\mathrm{y}$ el acceso a su patrimonio ancestral y recursos naturales ${ }^{39}$.

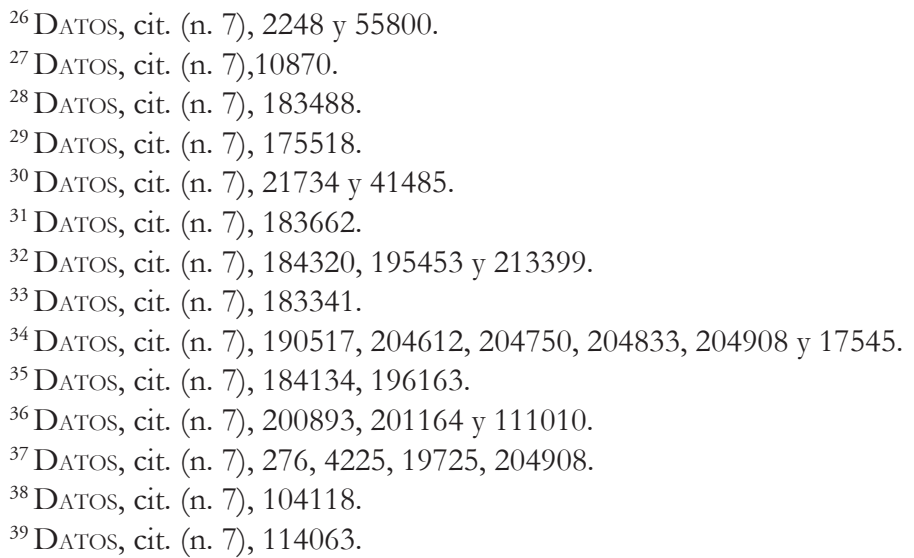




\section{Dilemas DE LA PROPIEDAD CHILENA EN LA DOCTRINA}

Según argumentan los profesores Eduardo Cordero y Eduardo Aldunate, no ha sido el concepto romano (o de derecho común) de propiedad, el que ha inspirado las codificaciones del siglo XIX, ya que su carácter "absoluto" en el constitucionalismo se concibe como una garantía de no afectación de los derechos de otros titulares y del ejercicio amplio de sus facultades, pero no implica limitar el poder de someter dichas facultades de uso y disposición a la regulación legislativa ${ }^{40}$. Confirma estas ideas el profesor Carlos Amunátegui Perelló, al explicar las diversas fuentes que usó Andrés Bello en la definición de propiedad del artículo 582 del Código Civil chileno. Sobre esta materia, dicho autor dice: "Bello tomó la definición antes de Pothier que de la codificación francesa. Su visión del ejercicio de la propiedad como limitado por el derecho ajeno tiene su origen en una doble conjunción, por una parte, la tradición castellana de las Partidas que establece que las cosas no pueden usarse de manera que dañen a otro, y por otra, las relaciones de vecindad a que hace referencia la limitación de ejercicio de Pothier. Según veremos, ambas tienen un mismo origen y responden a un único principio" ${ }^{1}$. Adicionalmente, el profesor Amunátegui Perelló coincide inicialmente con la argumentación de los profesores Cordero y Aldunate, reconociendo que en el Código Civil chileno existe una mayor tolerancia a las limitaciones a la propiedad, característica que lo distingue del modelo francés. Sobre esta importante cuestión, el mismo autor dice: "[el Código Civil chileno] al definir la propiedad, se aparta sutilmente de su modelo francés reemplazando la anodina prohibición de usar en contra de los reglamentos, por la más sustantiva interdicción de gozar y disponer contra el derecho ajeno. Esto constituye una interesante innovación que manifiesta una concepción de la propiedad limitada y poco usual en el contexto de su tiempo" ${ }^{\text {"42. }}$.

La dispersión de fuentes mencionada no significa que no existan principios que son comunes. Hay importantes coincidencias en el derecho castellano de las Partidas, el derecho romano y las ideas de Pothier. Así, Carlos Amunátegui Perelló ha señalado que en la idea de "derecho ajeno", que es la parte principal de la definición de propiedad de Bello, precisamente debe reconocerse esta confluencia, porque: "La limitación del dominio que contemplan las ya transcritas Partidas apunta en una dirección similar

${ }^{40}$ Cordero Quinzacara, Eduardo - Aldunate lizana, Eduardo, Evolución bistórica del concepto de propiedad, en Revista de Estudios Histórico-Jurídicos de la Pontificia Universidad Católica de Valparaíso 30 (2008), p. 384.

${ }^{41}$ Amunátegur Perelló, Carlos Felipe, Hacia un concepto de inmisiones en el derecho chileno, en Revista Chilena de Derecho 40 (2013), 1, pp. 509-510.

${ }^{42}$ Amunátegui Perelló, Carlos Felipe, cit. (n.41), p. 506. 
a Pothier. En efecto, la glosa de Gregorio López hace referencia al mismo principio, al evitar que a través de actos en lo propio se perjudique lo ajeno parafraseando el mismo apartado del Digesto. En este sentido, ambas tradiciones confluyen hacia un uso de la propiedad limitado, fundado, en ambos casos, en el mismo texto del cual el Derecho castellano y el francés son tributarios en este aspecto" ${ }^{43}$.

Sin embargo, Amunátegui Perelló discrepa del punto de vista de los profesores Cordero y Aldunate en la consideración de la propiedad como una libertad. Sobre esta cuestión, argumenta: "Cordero y Aldunate (2008) p. 359, opinan que la propiedad no es sino una forma de libertad. Aunque la definición históricamente provenga de ella, no podemos dejar de señalar que esta es una idea equivocada. En efecto, la libertad puede ser limitada por lo fáctico y lo jurídico (de ahí que se la defina como limitada por la fuerza o el Derecho), mientras que la propiedad nunca se limita por lo fáctico. Tan privado de libertad se encuentra el condenado por una sentencia como el secuestrado, mientras que el ladrón no priva del dominio al dueño, solo de la posesión. En efecto, el mérito de la concepción romana de la propiedad es separar de ella lo que es fáctico, que constituye la posesión. La posesión, en efecto, puede ser limitada por la fuerza, y el poseedor puede incluso perderla, mas nunca el dominio. El dominio y la libertad pertenecen a mundos conceptuales separados, y solo así se entiende que en las definiciones de propiedad sus límites sean siempre jurídicos, mientras que la libertad no"44.

El profesor Amunátegui Perelló utiliza la concepción romana, que distingue entre posesión y dominio, para sostener que la propiedad no debe ser considerada una forma de libertad. Pero en su justificación omite señalar que los profesores Cordero y Aldunate asumen esta vinculación entre propiedad y libertad, en todo su artículo, en relación con el proceso de la codificación y el constitucionalismo decimonónico. Esto consta en un subtítulo de su trabajo, que denominan: "El régimen liberal y la nueva concepción del derecho de propiedad" ${ }^{45}$, y se expone con más detalle en el artículo del Profesor Eduardo Cordero titulado "De la propiedad a las Propiedades: la evolución de la concepción liberal de la propiedad" 46.

Lo cierto es que la evolución de la propiedad en Chile a partir del siglo

${ }^{43}$ Amunátegui Perelló, Carlos Felipe, cit. (n.41), p. 512.

${ }^{44}$ Amunátegui Perelló, Carlos Felipe, cit. (n.41), p. 507.

${ }^{45}$ Cordero Quinzacara, Eduardo - Aldunate lizana, Eduardo, cit. (n. 40), pp. 345-388.

${ }^{46}$ Cordero Quinzacara, Eduardo, De la propiedad a las propiedades: La evolución de la concepción liberal de la propiedad, en Revista de Derecho de la Pontificia Universidad Católica de Valparaíso 31 (2008), pp. 493-525. La concepción liberal de la propiedad tiene una enorme complejidad porque se vincula a doctrinas económicas, historias y actitudes morales tal como explica en su trabajo Rose, Carol, Property as Storytelling: 
XIX es un proceso de creación institucional que contrasta con la realidad que existía en el territorio que hoy denominamos República de Chile. Con anterioridad a la conquista española, no existía una idea de propiedad unificada. Las formas principales de la propiedad en la cultura indígena eran colectivas. El régimen español consolidó un sistema mixto, donde las leyes españolas pusieron énfasis en algunas formas de propiedad privada, pero, a la vez, existieron toda clase de regímenes especiales, tales como los mayorazgos, las mercedes (o concesiones de tierra), la propiedad minera, la propiedad de las órdenes religiosas etc. ${ }^{47}$.

La idea de establecer una regulación general común para el derecho de propiedad en sus diversas formas es anterior al Código Civil, pudiendo al menos rastrearse hasta las disposiciones de la Constitución de 1833. Tal como hemos explicado en un trabajo anterior, las normas de la Constitución de 1833 reconocieron de un modo amplio la inviolabilidad de la propiedad ${ }^{48}$.

Esta amplitud en el reconocimiento de la propiedad constitucional tuvo entre sus propósitos la idea de retrotraer la vigencia de las normas que suprimieron los mayorazgos y otras formas tradicionales de la propiedad, y expresó un concepto constitucional de inviolabilidad de las propiedades, que entiende la institución dominical en plural. Esta idea se reconoció principalmente en el Artículo 12 número 5 de la Carta Fundamental de 1833, que dice: "Capitulo V. Derecho Público de Chile. Art. 12. La Constitución asegura a todos los habitantes de la República: (...) 50. La inviolabilidad de todas las propiedades, sin distinción de las que pertenezcan a particulares o comunidades, y sin que nadie pueda ser privado de su dominio, ni de una parte de ella por pequeña que sea, o del derecho que a ella tuviera, sino en virtud de sentencia judicial; salvo el caso en que la utilidad del Estado, calificada por una ley, exija el uso o enajenación de alguna; lo que tendrá lugar dándose previamente al dueño la indemnización que se ajustare con él, o se avaluare a juicio de hombres buenos"49. Además, en la Constitución de 1833 se agregó una sección especial dedicada a las garantías de la propiedad. Esta sección contiene diversas referencias a este derecho, tales como las siguientes: "Capitulo X. De las garantías de la seguridad y propiedad. Art. 146. La casa de toda persona que habite el territorio chileno es un asilo inviolable, y sólo puede ser allanada por un motivo especial determinado por la ley, y en virtud de autoridad competente. Art.147. Solo el Congreso puede

Perspectives from game theory, narrative theory, feminist theory, en Yale Journal of Law and Humanities 2 (1990), pp. 37-57.

${ }^{47}$ Ruiz-Tagle Vial, Pablo, cit. (n. 6), p. 133.

${ }^{48}$ Ruiz-Tagle Vial, Pablo, Cinco Repúblicas y una tradición. Constitucionalismo cbileno comparado (Santiago, Lom Ediciones, Colección Derecho en Democracia, 2016), pp. $58-62$.

${ }^{49}$ Valencia Avaria, Luis, Anales de la República (Santiago, Imprenta Universitaria, 1951), I, p. 164. 
imponer contribuciones directas o indirectas, y sin su especial autorización es prohibido a toda autoridad del Estado y a todo individuo imponerlas, aunque sea bajo pretexto precario, voluntario o de cualquiera otra clase (...). Art. 150. Ningún cuerpo armado puede hacer requisiciones, ni exigir clase alguna de auxilio, sino por medio de las autoridades civiles, y con decreto de estas (...). Art. 152. Todo autor o inventor tendrá la propiedad exclusiva de su descubrimiento o producción, por el tiempo que le concediere la ley; y si ésta exigiera la publicación, se dará al inventor la indemnización competente" 50 .

De lo anterior puede concluirse que en Chile, en fecha anterior a la introducción de las normas del Código Civil y de Comercio, ya existían normas y doctrinas constitucionales para reconocer y garantizar la propiedad o las propiedades ${ }^{51}$. Estas normas coexistieron con el derecho colonial común y español. Confirma esta opinión el famoso constitucionalista Manuel Carrasco Albano, quien, al comentar la Constitución de 1833 y sus normas referidas a la propiedad sin referirse al Código Civil ni al Código de Comercio, comparando el derecho común con la legislación española, dice: "Inviolabilidad de la propiedad. La garantía contenida en este artículo sobre la inviolabilidad de la propiedad es una de las condiciones fundamentales de toda sociedad civil i no ha hecho ninguna innovación en las disposiciones de la antigua legislación española. Siempre fue un principio de derecho común que la propiedad es sagrada, cualesquiera que por otra parte fueran los gravámenes y las injustas gabelas que pesaban sobre ella. Su inclusión entre las garantías de derecho público tiene más bien su importancia relativamente a las propiedades de las comunidades, que el artículo contrapone a las de los particulares. Con esa especificación se ha querido impedir la confiscación de las propiedades eclesiasticas o pertenecientes a los religiosos que desde el siglo XVI han sido víctimas de la reacción contra las riquezas y el fausto de órdenes religiosas" 52 .

En esta escueta explicación, Carrasco Albano plantea tres ideas principales: la identificación de la propiedad como fundamento de la sociedad civil (1); la vinculación entre las normas de propiedad de la reforma de 1833 con el derecho común y la legislación española colonial (2); y, la justificación de la cláusula constitucional como una forma de protección de la propiedad comunitaria, que la entiende como una forma de proteger la propiedad de las órdenes religiosas (3). Las ordenes religiosas, en cuanto a sus formas de

\footnotetext{
${ }^{50}$ Valencia Avaria, Luis, cit. (n. 49), p. 182.

${ }^{51}$ Aldunate Lizana, Eduardo, Derechos Fundamentales (Santiago, LegalPublishing, 2008), pp. 291-294.

${ }^{52}$ Carrasco Albano, Manuel, Comentarios a la Constitución Política de 1833 (2 edición, Santiago, Imprenta de la librería del Mercurio, Colección Obras de Derecho Público, Tribunal Constitucional de Chile, 2016), I, p. 50.
} 
propiedad, se vieron amenazadas por el surgimiento de los nuevos gobiernos republicanos $^{53}$. Una situación análoga a la que nos expone Carrasco Albano puede encontrarse en el origen del primer reconocimiento constitucional del derecho de propiedad en la república norteamericana de EE.UU., que se funda en la idea de impedir la arbitrariedad del gobierno y proteger todas las propiedades, incluso la de los partidarios de la monarquía inglesa, una vez que ha triunfado la independencia ${ }^{54}$.

En la obra de Jorge Huneeus titulada "La Constitución ante el Congreso", se contiene una nueva explicación sobre la propiedad de las comunidades religiosas y conventos, ya que, inspirado en doctrinas de derecho natural, concede al legislador ordinario, esto es, al Código Civil y al Código de Comercio, la función de regular la adquisición y conservación de la propiedad de las personas jurídicas. Huneeus dice: "Se ha incurrido en el error de creer que la Constitución asegura también la inviolabilidad de sus propiedades a las corporaciones. Así lo dice el señor Carrasco Albano en sus comentarios. Pero se sufre en esto una equivocación, porque el derecho de las corporaciones para adquirir y conservar bienes se rige por el Código Civil, y el de las sociedades anónimas por el Código de Comercio. Estas y aquéllas no son personas naturales, y no pueden, por lo tanto, tener derechos naturales. Su existencia es debida a la ley, y esta puede reglar soberanamente todas las condiciones de su desarrollo y de su extinción, lo cual no sucede con el hombre, cuya organización física, intelectual y moral es algo que el legislador debe necesariamente respetar, como ya lo hemos indicado" 55 .

Lo más significativo de estos escritos de Manuel Carrasco Albano y de Jorge Huneeus es que encontramos referencias al dilema doctrinario que envuelve al derecho de propiedad en Chile. El dilema consiste en la existencia de diversas normas del derecho de propiedad que emanan del derecho común, la legislación española y las distintas formas de la regulación constitucional. Estas formas alternativas de la propiedad no son necesariamente contradictorias, pero imponen criterios diferentes, tal como anota con gran perspicacia en sus observaciones el jurista Jorge Huneeus.

El dilema doctrinario de la concepción múltiple y a veces equívoca de la propiedad no se disuelve con la entrada en vigencia de la Constitución de 1925, sino que, más bien, ésta acentúa la diferencia entre la concepción constitucional de propiedad y la que emana del Código Civil. En la Consti-

${ }^{53}$ Carrasco Albano, Manuel, cit. (n. 52), p. 51.

${ }^{54}$ ELY, J. W., The guardian of every other right. A constitutional history of property rights (New York, Oxford, Oxford University Press, 2008), pp. 34-35.

${ }^{55}$ Huneeus, Jorge, La Constitución ante el Congreso ( $2^{\circ}$ edición, Santiago, Imprenta Cervantes, 1890, Colección Obras de Derecho Público, Tribunal Constitucional de Chile, 2016), II, p. 109. 
tución de 1925 se crean nuevas formas de entender la propiedad vinculadas a la idea de función social, que constituyen el gran tema del derecho constitucional chileno durante prácticamente todo el siglo XX. Ésta incluye la reforma agraria, la nacionalización de la propiedad minera y la formación de sus áreas públicas, privadas y mixtas, la expropiación de la banca, de las telecomunicaciones y de los sectores estratégicos del país ${ }^{56}$.

En la Constitución vigente en Chile, la concepción constitucional de la propiedad se reconfigura y al menos se aparta de la visión del derecho civil en los puntos siguientes: (1) La propiedad como derecho fundamental y derecho humano y su relación con la dignidad (arts. 5 y 17 de la Declaración de Derechos Humanos y art. 21 del Pacto de San José); (2) La garantía de acceso a la propiedad (art. 19 No. 23 C. Pol.); (3) La propiedad constitucional que comprende toda clase de bienes (Art. 19 No. 24 C. Pol.); (4) La función social de la propiedad (art. 19 Nos. 19, 24 y 26 C. Pol.); (5) La regulación de la expropiación (art. 19 No. 24 C. Pol.); (6) Atributos, facultades y privación, perturbación y/o amenaza de la propiedad (art. 19 No. 24 y art. 20 C. Pol.); (7) La regulación de la propiedad intelectual y otras propiedades especiales (Art. 19 Nos. 24 y 25 C. Pol.); (8) Los límites, obligaciones e intereses colectivos de la propiedad (art. 19 No.24 C. Pol.); (9) El contenido esencial de la propiedad (art. 19 No. 26 C. Pol.); y, (10) Acciones, regímenes de excepción y disposiciones transitorias sobre propiedad (arts. Nos. 20, 43 y 44 y disposiciones Segunda y Tercera transitoria C. Pol. $)^{57}$.

Esta evolución del concepto constitucional de propiedad en la Constitución vigente ha sido analizada en diversos trabajos de doctrina jurídica chilena. Por ejemplo, en relación con la faz subjetiva y objetiva de la propie$\mathrm{dad}$, la distinción entre cosas corporales e incorporales, la función social y el contenido esencial pueden mencionarse los trabajos del Profesor Eduardo Cordero $^{58}$. El trabajo del Profesor Alejandro Vergara ha tratado la idea de la “propietarización" de los derechos en Chiles9. También, el Profesor Lautaro Ríos ha escrito sobre la función social de la propiedad como forma principal de limitación del dominio en el ámbito constitucional ${ }^{60}$, y están los estu-

${ }^{56}$ Ruiz-Tagle Vial, Pablo, cit. (n. 6), pp. 133-144.

${ }^{57}$ Ruiz-Tagle Vial, Pablo, cit. (n. 6), pp. 223-234.

${ }^{58}$ Cordero Quinzacara, Eduardo, La dogmática constitucional de la propiedad en el derecho chileno, en Revista de Derecho de la Universidad Austral de Chile 29 (2006), 1, pp. 125-148.

${ }^{59}$ Vergara Blanco, A., La propietarización de los derechos, en Revista de Derecho de la Pontificia Universidad Católica de Valparaíso 14 (1991), pp. 281-291.

${ }^{60}$ Ríos, Lautaro, El principio constitucional de la función social de la propiedad, en Revista de Derecho y Jurisprudencia (Santiago, Edición Bicentenario, Derecho Civil, Bienes, Editorial Thomson Reuters, 2010), pp. 116.136. 
dios de Rodrigo Bustos sobre la función social desde el punto de vista del derecho internacional de los derechos humanos ${ }^{61}$. Son también un valioso aporte las reflexiones de Enrique Evans sobre las opiniones multiformes de los abogados comisionados por la dictadura para redactar el texto constitucional de 1980 y lo que fueron sus opiniones sobre la propiedad ${ }^{62}$. Así, inspirado en la obra de Enrique Evans, el Profesor Humberto Nogueira ha concebido el derecho de propiedad en su relación con ciertos bienes jurídicos de carácter patrimonial, entre los cuales incluyen las normas sobre libre actividad económica y libre adquisición de bienes (artículo 19 números 21 y 23 C. Pol.); el derecho a no ser discriminado por las autoridades (artículo 19 número $22 \mathrm{C}$. Pol.); el derecho de propiedad (artículo 19 número $23 \mathrm{C}$. Pol.) y el derecho de propiedad sobre las creaciones intelectuales (artículo 19 número 25 C. Pol.) $)^{63}$. Del mismo modo, por su riqueza conceptual, las ideas de la propiedad constitucional en Chile se benefician de los estudios de Alejandro Guzmán o de Enrique Brahm, sobre el sentido de la idea de cosa incorporal en el Art. 19 número 24 de la Carta Fundamental o sobre la concepción del Código Civil Francés sobre la propiedad. A ellos se agrega el comentario de Hernán Corral referido al primero de estos trabajos ${ }^{64}$.

En síntesis, en la doctrina jurídica chilena, el dilema sobre la concepción de la propiedad en Chile se abre al menos en cinco direcciones principales: fuentes directas del derecho romano (1); fuentes doctrinarias inspiradas en la obra de Pothier, algunas de las cuales coinciden con el derecho común (2); fuentes que emanan de la legislación codificada francesa, particularmente del artículo 544 del Código Civil francés (3); fuentes del derecho castellano, expresado de manera preferente en las Siete Partidas (4); y, finalmente, coexistiendo con todas ellas, fuentes derivadas de las normas constitucionales sobre el derecho de propiedad (5). Esta enumeración en

${ }^{61}$ Bustos, Rodrigo, Función socialy límites del derecho de propiedad. Temas emergentes en el derecho internacional de los derechos humanos, en Estudios de Derecho Privado. Libro en homenaje al profesor Gonzalo Figueroa Yáñez. (Santiago, Editorial Jurídica de Chile, 2008), pp. 369-393.

${ }^{62}$ Evans, Enrique, Los derechos constitucionales (Santiago, Editorial Jurídica de Chile, 1999), III, pp. 213-231.

${ }^{63}$ Nogueira, Humberto, Instituciones Politicas y Teoría Constitucional (Talca, Editorial Universidad de Talca, 2001), II, p. 392.

${ }^{64}$ GuZmán, Alejandro, Las cosas incorporales en la doctrina y en el derecho positivo (Santiago, Editorial Jurídica de Chile, 1995), pp. 117-148, 235-256. Brahm, Enrique, La perversión de la cultura chilena durante el gobierno de la Unidad Popular. "resquicios legales" y derecho de propiedad, en Revista Chilena de Historia del Derecho 18 (1999-2000), p. 425. Corral, Hernán, Propiedad y cosas incorporales. Comentarios a propósito de una reciente obra del profesor Alejandro Gurmán Brito, en Revista Chilena de Derecho 23 (1996), 11, pp. 13-18. 
ningún caso es exhaustiva. Es nada más que una constatación de que la concepción del derecho de propiedad en la doctrina chilena se funda en fuentes que tienen un carácter multiforme, y que adquieren en muchos casos el carácter de un verdadero dilema. A este concepto deben agregarse los principios, normas y doctrinas referidas a propiedades especiales. Estas fuentes diversas demuestran un dilema doctrinario sobre el derecho de propiedad que afecta también su aplicación a casos concretos. La expresión en el ámbito constitucional de estos dilemas de aplicación jurisprudencial es lo que se analiza en la sección siguiente.

\section{Dilemas de la PRopiedad ChILENA EN LA JURISPRUdenCia}

La jurisprudencia constitucional chilena, en lo que se refiere a la definición de propiedad, no tiene referencias a tratados internacionales y tiende a no concebir la propiedad como un derecho fundamental o un derecho humano. Además, en algunos casos, mezcla criterios del Código Civil sobre la propiedad de las cosas corporales con criterios referidos a cosas incorporales (tales como el "cargo" o la "imagen"). También predominan los criterios procesales de la acción de protección del artículo 20 de la Constitución vigente en Chile, mucho más que los criterios sustantivos de la propiedad. La jurisprudencia también trata el alcance del principio de reserva legal igual que la distinción entre afectación en su esencia y lo que constituye impedimento para el libre ejercicio de un derecho; la idea que los derechos fundamentales no son absolutos y tienen límites; los criterios para admitir restricciones; y el examen de proporcionalidad de la limitación de derechos por vía legal y/o reglamentaria; entre otras materias ${ }^{65}$. La jurisprudencia de los tribunales ordinarios chilenos, y, por cierto, de la Corte Suprema, de la Contraloría General de la República, de los Tribunales especiales y del TC, validan la tesis que la Constitución permite que el legislador cree y estatuya diferentes formas de la propiedad. Sin embargo, esta cuestión de la diversidad de las propiedades, aunque se reconoce en principio, no se asume plenamente en las decisiones de aplicación. En particular, existe una serie de decisiones dictadas por el TC que ponen en duda esta idea. En la jurisprudencia del TC se ha producido una controversia entre sus integrantes, porque algunos han sostenido en sus opiniones una noción diversificada de propiedad y aceptan que este derecho está sometido a reglamentación en forma flexible. En cambio, otro grupo argumenta que la concepción de propiedad es unificada y reforzada, y que impone requisitos estrictos sobre la reglamentación que puede afectarla. Esta última posición es hoy mayoritaria.

Estas dos formas principales de concebir la propiedad se han expresado en las sentencias del TC del caso Santa Beatriz (caso resuelto por el TC el 29 de

${ }^{65}$ Ruiz-Tagle Vial, Pablo, cit. (n. 6), pp. 234-239. 
Enero de 2014, con el rol STC 2299-2012, en adelante denominado Santa Beatriz), y de los casos Molinera (casos resueltos por el TC el 27 de Enero 2015 bajo los roles STC 2643-2014 y 2644-2014, en adelante denominado Molinera), y al caso Curtidos (caso resuelto por el TC el 10 de septiembre 2015 bajo el rol STC 2684-2014, en adelante denominado Curtidos). En estos tres casos se aprecia en toda su intensidad el dilema jurisprudencial que embarga la propiedad constitucional en Chile, y, por eso, analizo estas sentencias en la sección siguiente.

\section{El caso Santa Beatriz}

En el primer caso, que hemos denominado Santa Beatriz, la cuestión jurídica se refiere a la petición de que se declaren inaplicables por inconstitucionales los artículos 29 y 30 de la Ley $\mathrm{N}^{\circ} 17.288$, sobre Monumentos Nacionales. La opinión mayoritaria del TC -que se impone por existir un empate en la votación de los ministros, que implica rechazar el requerimiento- argumenta rechazar el requerimiento, fundando su opinión en una serie de precedentes constitucionales sobre las limitaciones al derecho de propiedad, incluida una referencia a su contenido esencial. En apoyo del voto de mayoría, se citan las sentencias del TC casos STC roles 245-1996 y 246-9666, 943-200767,

${ }^{66}$ Fallo disponible [en línea]: http://www.tribunalconstitucional.cl/expediente file:///C:/Users/pruiztagle/Downloads/48080.pdf (consultado por última vez el 28 de febrero de 2018), en adelante denominado Santa Beatriz, p. 20: "el inciso segundo del numeral $24^{\circ}$ del artículo 19 de la Constitución Politica configura las limitaciones y obligaciones fundadas en la función social de la propiedad cuyas causales han sido señaladas especificamente por el legislador, a saber, los intereses generales de la Nación, la seguridad nacional, la utilidad y salubridad públicas y la conservación del patrimonio ambiental. En concepto de este Tribunal, "la función social de la propiedad significa que ésta tiene un valor individual y social por lo que debe estar al servicio de la persona y de la sociedad. El dominio además de conferir derechos, impone deberes y responsabilidades a su titular. Estos deberes y responsabilidades que buscan armonizar los intereses del dueño con los de la sociedad, constituyen la función social de la propiedad". Asimismo, ha precisado que "las limitaciones suponen el establecimiento de determinadas cargas al ejercicio de un derecho, dejándolo subsistente en sus facultades esenciales." (STC roles $N^{\circ} s 245-246$, considerandos $22^{\circ}$ y 25\%). Esta Magistratura ha recordado también que, en el Memorándum de 16 de agosto de 1978, dirigido por la Comisión de Estudio de la Nueva Constitución al Presidente de la República, se dice que "la función social es inherente al derecho de propiedad y está implícita en él. Supone que el derecho debe ser ejercido de acuerdo con el fin que le es propio y en armonía con los intereses colectivos (STC roles $\mathrm{N}^{\circ}$ s 245-246, considerando $27^{\circ}$ )".

${ }^{67}$ Santa Beatriz, cit. (n. 66), p. 23: "9. Que, desde esta perspectiva, la doctrina de los iuspublicistas junto a la jurisprudencia constitucional y judicial están contestes en que la imposición de limitaciones u obligaciones en razón de la función social de la propiedad no puede fundarse en el mero capricho del legislador-único llamado a establecerlas-y además no puede implicar que las limitaciones y obligaciones que se imponen a la propiedad se transformen en una privación del derecho, del bien sobre el que recae o de alguno de sus atributos esenciales, en virtud de lo dispuesto en el inciso tercero del artículo $19 \mathrm{~N}^{\circ} 24^{\circ}$ de la Carta Fundamental. Todo lo anterior excedería el parámetro constitucional. Este 
exceso de poder no se compensa con dinero ni con indemnizaciones ad-hoc, sin perjuicio de que genere responsabilidad pecuniaria (STC Rol $N^{\circ}$ 943, considerando 16²)".

${ }^{68}$ SANTA BEATRIZ, cit. (n. 66), p. 25. "El adecuado equilibrio entre derecho de propiedad privada y otros derechos fundamentales que puedan estar comprometidos en el conflicto concreto de que se trata, envolviendo estos últimos un claro interés social que supera el mero interés individual del propietario privado. Asi ocurriría, por ejemplo, si se encuentran en contraposición el derecho de propiedad y el derecho a vivir en un medio ambiente libre de contaminación, derecho este último que permite establecer limitaciones legitimas al derecho de propiedad privada en razón de la conservación del patrimonio ambiental. Al respecto, nuestra Magistratura ha afirmado: "La conservación de los caudales de aguas y la adopción por parte del Estado de todas las medidas para evitar su agotamiento están comprendidas dentro de la preservación del patrimonio ambiental, como uno de los elementos que comprende la función social de la propiedad (STC Rol N¹309, considerando $6^{\circ}$ )".

${ }^{69}$ SANTA BEATRIz, cit. (n. 28), p. 36: "El principio de proporcionalidad, pues el gravamen o detrimento -especialmente económico- que se deriva de la limitación que se impone no debe ser de tal naturaleza que haga desaparecer el derecho o deje sin posibilidad de concretar el ejercicio de sus atributos esenciales, pues, en tal caso, se estaría frente a una expropiación en los términos regulados por el inciso tercero del articulo $19 \mathrm{~N}^{\circ} 24^{\circ}$ de la Carta Fundamental, figura que, en el Derecho Comparado, se denomina "expropiación regulatoria." En este sentido, este Tribunal ha sostenido: "Una limitación a la propiedad es proporcional cuando impone al dueño una obligación indispensable para la satisfacción de una finalidad de interés público. La proporcionalidad del medio empleado aparece de manifiesto si opera cuando no existan alternativas disponibles, sólo para fines determinados y previa intervención de la autoridad, con audiencia del afectado, y existe una instancia de reclamo ante los tribunales de justicia (STC Rol No 1215, considerando 28०)".

${ }^{70}$ SANTA BeAtriz, cit. (n. 66), p. 34: "21․ Que se cumple, de esta manera, con las exigencias que, en materia de afectación de los derechos y, en particular del derecho de propiedad, ha establecido esta Magistratura al señalar que: "Las disposiciones legales que regulen el derecho de propiedad y de libertad ambulatoria deben reunir los requisitos de "determinación y especificidad". El primero exige que los derechos que puedan ser afectados se señalen, en forma concreta, en la norma legal; y el segundo requiere que la misma indique, de manera precisa, las medidas especiales que se pueden adoptar con tal finalidad. Por último, los derechos no podrán ser afectados en su esencia, ni imponerles condiciones, tributos o requisitos que impidan su libre ejercicio. Cumplidas que sean dichas exigencias, es posible y lícito que el Poder Ejecutivo haga uso de su potestad reglamentaria de ejecución, pormenorizando y particularizando, en los aspectos instrumentales, la norma para hacer asi posible el mandato legal (STC Rol $N^{\circ} 325$, considerando 40 $0^{\circ}$ )'-

${ }^{71}$ Santa BeAtriz, cit. (n. 66), p. 36: "24‥ Que, finalmente, para desechar una posible infracción constitucional al derecho de propiedad de la requirente, es necesario recordar que sólo una limitación o regulación de gran magnitud puede constituir una privación de la propiedad dando lugar a la indemnización correspondiente. Tal como ha resuelto este Tribunal, "la magnitud de la regulación no resulta indiferente. Por una parte, porque toda regulación o limitación priva al propietario de algo. A partir de la regulación, alguna autonomía, privilegio, ventaja o libertad que tenía, desaparece para su titular. Si tuviéramos por propiedad cada aspecto de esa autonomía, privilegio, ventaja o libertad, la regla constitucional que permite limitar la propiedad equivaldría a letra muerta, lo que se contradiría con múltiples fallos del Tribunal Constitucional que han tolerado, en determinados casos y bajo ciertas condiciones, la regulación de la propiedad. Por el contrario, legitimar cualquiera regulación o limitación, sin considerar su impacto sobre la propiedad, desnaturalizaría la protección 
parte, en el voto de minoría del caso Santa Beatriz se cita en apoyo de sus argumentaciones el artículo 925 del Código Civil ${ }^{72}$ y los casos STC roles 191983 y $1185-2008^{73}, 325-2001^{74}, 334-01^{75}, 370-2003^{76}, 226-1996$ y $280-98^{77}, 198-1994^{78}, 389-2001$ y $433-2005^{79}$.

de este derecho fundamental ("la limitación tiene sus límites", para usar una expresión ya clásica del derecho anglosajón). El carácter esencial de lo privado en virtud de la regulación es un parámetro siempre útil para hacer la distinción y debe utilizarse aunque se determine que, prima facie, se trata de una regulación (STC Rol $N^{\circ} 505$, considerandos $22^{\circ}$ y $23^{\circ}$ )".

${ }^{72}$ Santa Beatriz, cit. (n. 66), p. 43: "No por otra razón el Código Civil-entre otras normas citables- dice que la posesión del suelo se prueba "por hechos positivos, de aquellos a que sólo da derecho el dominio", tales como "la construcción de edificios", primordialmente en áreas urbanas, o las "plantaciones o sementeras", especialmente en zonas rurales, si se atiende a la naturaleza de los respectivos terrenos (articulo 925)”.

${ }^{73}$ SANTA Beatriz, cit. (n. 66), p. 39: "Es este ecuánime equilibrio -entre bien común y derechos constitucionales- un referente capital con fuerza obligatoria directa e inmediata, según ha apuntado este Tribunal (roles $N^{\circ}$ s. 19, considerando $9^{\circ}$, y 1185, considerandos $11^{\circ}$ y $12^{\circ}$ ). Que, cual binomio inescindible, se proyecta y permea a todo el ordenamiento jurídico en su integridad, implicando que a las leyes no les basta invocar algún interés colectivo o universal, como excusa para ignorar o preterir los derechos que "asegura" efectivamente el texto fundamental (articulo 19)".

${ }^{74}$ SANTA BeAtriz, cit. (n. 66), p. 39: “... frente al aparente conflicto entre el legítimo ejercicio de la libertad de las personas y la consecución por el Estado de un interés público, falso dilema que acaba indefectiblemente con la preeminencia absoluta de este último, en circunstancias que no se concibe - sin herir la justicia y la lógica - que a costa de males individuales pueda lograrse algún bienestar general (roles $N^{\circ}$ s. 325, considerando $6^{\circ}$, y 591, considerando $4^{\circ}$ ). Por lo que, de afectarse un bien privado por transparentes razones de utilidad general, el propietario debe ser amparado sin sufrir menoscabo, recibiendo la indemnización que ocupe el equivalente lugar jurídico dentro de su propiedad (Avelino León Hurtado, "Influencia del derecho público en la propiedad privada inmobiliaria", Revista de Derecho y Jurisprudencia, Edición Bicentenario, Doctrinas Esenciales en Derecho Civil, 2010, pág. 199)".

${ }^{75}$ SANTA BeAtriz, cit. (n. 66), p. 40: “... a efectos de relacionar el citado inciso cuarto del artículo $1^{\circ}$, con el articulo 19, $N^{\circ} 24$, constitucional, fuerza insistir que la Carta Fundamental vigente - si se atiende a su texto y antecedentes- robusteció el régimen jurídico atinente a la propiedad (roles $N^{\circ}$ s. 334, considerando $12^{\circ}$, y 467 , considerando $35^{\circ}$ ): reconociendo-primero- que el dominio es un derecho con un claro e inequivoco contenido sustancial, al delimitar ella misma sus atributos y facultades básicas, sobre las cuales hay asimismo propiedad, y resguardándolo -luegocon una garantía exigida en la propia Constitución, al indicar que solo la ley puede regular o limitar su ejercicio. Y esto último, únicamente si concurre alguna de las causales que autorizan limitar (inciso segundo). El texto supremo, además, a los efectos de exigir que medie una expropiación, entiende que la privación del dominio no solo acontece cuando se quita o despoja al dueño de suyo, en su totalidad, sino también cuando al titular -aun conservando nominativamente tal carácter- se le desposee, parcialmente, de alguno de los atributos o facultades esenciales que caracterizan la propiedad, según ba recordado también este Tribunal ( $\mathrm{Rol} \mathrm{N}^{\circ} 334$, considerando $\left.19^{\circ}\right)$ ".

${ }^{76}$ SANTA BeAtriz, cit. (n. 66), p. 48: "170) Que, entre los pronunciamientos basilares de este Tribunal, está aquel donde se precisó "que establecer, crear o instituir una obligación que afecte al dominio presupone, lógica e ineludiblemente, que el legislador no se limite a ello sino que, además, 
Entre el voto de mayoría y el de minoría del caso Santa Beatriz, sólo coincide la referencia a los precedentes en relación con el caso STC rol 3252001. Ningún otro de los casos citados por el voto de mayoría es siquiera mencionado en la opinión minoritaria. Además, en el voto de mayoría, la referencia al caso STC rol 325-2001 se hace respecto del considerando 40, donde se ha expresado la síntesis de las condiciones que permiten la afectación de un derecho fundamental en el ejercicio de la potestad reglamentaria por parte la autoridad ejecutiva. En cambio, en el voto de minoría, es el considerando $6^{\circ}$ del caso STC rol 325-2001 el que inspira esta opinión, y se menciona para afirmar que los males individuales nunca puedan generar un bien general. Se trata paradojalmente de conclusiones muy distintas, quizás antagónicas, que emanan de la referencia del mismo caso STC rol 325-2001.

\section{Los casos Molinera}

En el análisis de las sentencias de los casos que hemos denominado Molinera, se muestra un paralelismo en los considerandos y la argumentación jurídica, y se refieren a la misma cuestión jurídica, esto es, que se declare como inaplicable por inconstitucional el artículo 62 y 160 de la Ley de Urbanismo y Construcción, que autoriza decretar el traslado de una empresa.

la configure en sus aspectos y elementos definitorios o característicos, trazando, con adecuada densidad normativa, en qué consiste el deber que impone, cuál es el motivo de función social que lo justifica, cuáles son sus delimitaciones, sobre la base de qué supuestos fácticos se torna procedente exigirla, cuál es la autoridad competente para llevarla a efecto y controlarla, a quiénes y por qué motivos se les exime de ella, etc. (Rol $N^{\circ} 370$, considerando 31, cursivas añadidas)".

${ }^{77}$ SANTA BEATRIZ, cit. (n. 66), p. 48: "La jurisprudencia en esta sede ha advertido que las restricciones a un derecho asegurado solo pueden establecerse "en los casos o circunstancias que en forma precisa y restrictiva indica la Carta Fundamental; y que, además, tales limitaciones deben estar señaladas con absoluta precisión, a fin de que no sea factible una incorrecta o contradictoria interpretación. Asimismo, esa exigida precisión debe permitir la aplicación de las restricciones impuestas de una manera igual para todos los afectados, con parámetros incuestionables y con una indubitable determinación del momento en que aquellas limitaciones nacen o cesan (Rol $N^{\circ} 226$, considerando $47^{\circ}$. Criterio reiterado en Rol $N^{\circ} 280$, considerando 29०)".

78 Santa BeAtriz, cit. (n. 66), p. 49: “18) Que, en términos más generales, esa jurisprudencia también ha reprobado una ley cuando deja abandonado el goce efectivo de los derechos y libertades a los poderes absolutamente discrecionales que pueda acometer, indeterminadamente, un órgano de la Administración, máxime cuando los motivos que autorizan su actuación solo dependen de la apreciación libre y subjetiva de los agentes o funcionarios que participan en su aplicación (Rol $N^{\circ} 198$, considerando $\left.10^{\circ}\right)$ ".

${ }^{79}$ SANTA BEATRIZ, cit. (n. 66), p. 49: "La ley es inconstitucional-ha recalcado- cuando amaga o desampara aquellos derechos pasibles de restricciones a consecuencia de habilitaciones irrestrictas conferidas a la autoridad, sin trazar esa ley las pautas o parámetros objetivos y controlables que garanticen que el órgano gubernamental se ha circunscrito a ellos, asumiendo la consecuente responsabilidad cuando los ha transgredido $\left(\mathrm{Rol} \mathrm{N}^{\circ} 389\right.$, considerando $25^{\circ}$, doctrina posteriormente aplicada en Rol $N^{\circ} 433$, considerandos $30^{\circ}, 31^{\circ}$ y $34^{\circ}$ )". 
El voto de mayoría en los casos Molinera rechaza el requerimiento y entiende la propiedad constitucional como diversificada y sometida a regulación, y funda su opinión en la jurisprudencia anterior emanada de los precedentes del TC de los casos STC roles 370-2003 ${ }^{80}, 1298-2009^{81}$,

${ }^{80}$ Fallo disponible [en línea]: http://www.tribunalconstitucional.cl/expediente file://C:/Users/pruiztagle/Downloads/50904.pdf y file://C:/Users/pruiztagle/ Downloads/50905.pdf, (Consulta 28.2.2018), en adelante denominados Molinera, p. 32: "CUADRAGESIMO PRIMERO: Que el inciso segundo del $N^{\circ} 24^{\circ}$ del artículo 19 de la Constitución exige que el modo de adquirir la propiedad, de usar, gozar y disponer de ella y las limitaciones y obligaciones que deriven de su función social serán establecidos por ley, lo que da origen a una reserva legal precisa y vigorizada (STC 370/03, c. 40). Dicha reserva impone la regulación legal de la adquisición de la propiedad, facultades de su titular y las restricciones que debe soportar". Ver también otra referencia al caso 370 en: "CUADRAGESIMO QUINTO: Que la pregunta anterior ha sido entendida por la jurisprudencia de esta Magistratura como una cuestión relativa a la adecuada o debida densidad normativa. La exigencia de la debida densidad normativa pretende que la norma legal que forme parte de la reserva legal establecida por el constituyente contenga un mandato que impida a normas infra legales o decisiones administrativas disponer del objeto regulado con una potestad equivalente a la del legislador. En estos términos, la reserva legal creada por el articulo 19, $N^{o} 24^{\circ}$, inciso segundo, del Texto Fundamental permite afirmar que "establecer, crear o instituir una obligación que afecte al dominio presupone, lógica e ineludiblemente, que el legislador no se limite a ello sino que, además, la configure en sus aspectos y elementos definitorios o característicos, trazando, con adecuada densidad normativa, en qué consiste el deber que impone, cuál es el motivo de función social que lo justifica, cuáles son sus delimitaciones, sobre la base de qué supuestos fácticos se torna procedente exigirla, cuál es la autoridad competente para llevarla a efecto y controlarla, a quiénes y por qué motivos se les exime de ella (...)" (STC 370/2003, c. $30^{\circ}$ ). Tratándose de esta reserva legal, "el legislador debe precaver hasta los indicios de una deslegalización constitucionalmente probibida, evitando incurrir, por ende, en meros enunciados normativos, en disposiciones abiertas, en suma, en normas carentes de la determinación y especificidad que (...) son requisitos esenciales para que la potestad reglamentaria de ejecución se balle legitimamente habilitada" (STC 370/2003, c. 31 ${ }^{\circ}$ ). Atendido lo anterior, el legislador "tiene que llegar al desarrollo de los principios y normas que dicta con un nivel de minuciosidad mayor que tratándose de materias en que la reserva legal es común u ordinaria. Respetando los criterios de generalidad, abstracción, igualdad, carácter innovador y cualidad básica que singularizan a la ley en el sistema jurídico, al legislador le corresponde normar, con amplitud y profundidad, todo cuanto la certeza o seguridad jurídica exige en relación con el establecimiento y configuración de las obligaciones que se imponen al dominio con motivo de la función social que ba de servir" (STC 370/2003, c. $34^{\circ}$ ). Por lo mismo, en el ámbito del derecho de propiedad, la Constitución exige al legislador regular con la densidad normativa adecuada, sin generar una habilitación excesiva a favor de la potestad reglamentaria de ejecución o permitir una deslegalización probibida por la Carta Fundamental".

${ }^{81}$ Molinera, cit. (n. 80), p. 35: "CUADRAGESIMO SEXTO: Que la exigencia anterior debe ser conciliada con la necesidad de entregar al legislador la posibilidad de construir estatutos jurídicos de propiedad diferenciados que puedan cumplir de modo adecuado con el deber de proteger la certeza o seguridad jurídica en armonía con la singularidad del derecho de propiedad tutelado conforme con la Constitución. Recordemos que el inciso primero del $N^{\circ} 24^{\circ}$ del artículo 19 de la Constitución asegura el derecho de propiedad "en sus diversas especies", expresión, esta última, que ha sido interpretada por esta Magistratura como expresión de la facultad atribuida 
$334-2001^{82}, 1295-2008^{83}, 1215-2008^{84}$. También, copulativamente, menciona los casos STC roles 1182-2008, 1193-2003, 1201-2008, 1541-2009 y 1141-2008 ${ }^{85}$. Concluye sus referencias de jurisprudencia con la mención

al legislador para crear estatutos de propiedad diferenciados. Asi, el Tribunal Constitucional ha sostenido que "el constituyente se mantiene neutro frente a las preferencias constitutivas del legislador al momento de definir "el modo de adquirir la propiedad, de usar, gozar y disponer de ella y las limitaciones y obligaciones que deriven de su función social". No existe una legislación que baya sido erigida por el constituyente en modelo de todas las demás propiedades. Ello babría significado constitucionalizar una determinada legislación; rigidizar las definiciones del legislador; y abrir un debate sobre la protección de las propiedades constituidas a partir de un diseño propio, distinto a ese pretendido modelo comín (STC 1298/2010, c. 44.)”. Ver también referencia al caso 1298 en: "QUINCUAGESIMO OCTAVO: Que la Constitución faculta a la ley para establecer limitaciones y obligaciones que graven el ejercicio del derecho de propiedad. Ellas son restricciones o acotamientos al ejercicio, común u ordinario, de este derecho (STC 1298/2010, c. 49). Citando a José Luis Cea, esta Magistratura ha señalado que mientras las limitaciones son, en general, probibiciones de hacer algo, las obligaciones son mandatos de hacer y ambas deben fundarse en la función social de la propiedad (STC 1298/2010, c. 49)".

${ }^{82}$ Molinera, cit. (n. 80), p. 45: "QUINCUAGESIMO NOVENO: Que la Constitución sólo ha reconocido como función social derivada de la propiedad un listado taxativo de sus manifestaciones, a saber: los intereses generales de la Nación, la utilidad y salubridad públicas y la conservación del patrimonio ambiental. Como se ha sostenido antes, "la Constitución sólo ba previsto la procedencia de limitaciones y obligaciones para las determinadas expresiones de la función social del dominio que ha señalado y toda otra restricción es inconstitucional (STC 334/2001, c. $\left.21^{\circ}\right)$ ".

${ }^{83}$ Molinera, cit. (n. 80), p. 45: "Las limitaciones y obligaciones previstas por los artículos 62, inciso segundo, y 160 de la LGUC caben dentro de la utilidad y salubridad públicas y la conservación del patrimonio ambiental. La utilidad pública se refiere, en este contexto, a que el limite u obligación impuesto por la ley debe beneficiar a la sociedad y su fin excede el propósito de sus miembros (STC 1295, cs. $43^{\circ}$ y $54^{\circ}$ ). La salubridad pública como expresión de la función social de la propiedad introduce en ésta el propósito de promover y proteger la salud de la población. La conservación del patrimonio ambiental como expresión de la función social de la propiedad la grava con aquello que es necesario para preservar los elementos del entorno que pertenecen a todos los seres bumanos y debe seguir perteneciendo a la humanidad en el futuro".

${ }^{84}$ MOLINERA, cit. (n. 80), p. 50: "SEXAGESIMO QUINTO: Que el examen de necesidad consiste en examinar si el precepto legal ha empleado un medio necesario o al menos adecuado para alcanzar un propósito constitucionalmente legítimo que quede comprendido, en el caso de autos, en la función social de la propiedad (STC 1215/09, c. 27º)". Ver también referencia al caso STC rol 1215 en: "SEXAGESIMO SÉPTIMO: Que, una vez, revisada la necesidad de la regulación adoptada por el precepto legal cuestionado, cabe realizar un examen de idoneidad, esto es, si el medio escogido por el legislador es el adecuado para alcanzar el propósito amparado por la Constitución (STC 1215/2009, c. 27º)". Ver también referencia a STC caso Rol 1215 en considerando SEPTUAGESIMO OCTAVO mencionado en la nota siguiente.

${ }^{85}$ Molinera, cit. (n. 80), p. 63. "SEPTUAGESIMO OCTAVO: Que, una vez. revisada la necesidad e idoneidad de la regulación contenida en los preceptos legales cuestionados, cabe realizar un examen de proporcionalidad, esto es, si el menoscabo o limitación impuesto 
de los casos STC roles 56-1988, 1863-2012, 1986-2012, 1991-2012, y 1993-2012 ${ }^{86}$. Además, el voto de mayoría cita para fundar su opinión la doctrina que emana de los trabajos de Mathew Mirow ${ }^{87}$, Pedro José Rodríguez ${ }^{88}$ y Raúl Bertelsen ${ }^{89}$.

Por su parte, el voto de minoría en los casos Molinera se funda en una concepción de la propiedad que es unificada y reforzada, y que impone requisitos estrictos sobre la reglamentación. Cita la jurisprudencia del TC que emana de los casos STC roles 370-2003 ${ }^{90}$, 505-2006 y 506-2006 ${ }^{91}$.

al ejercicio del derecho tiene armonía con el beneficio que se obtiene en el logro del fin lícito que se persigue (STC 1182, c. 21ㅎ también SSTC 1193, 1201, 1541). Como ha señalado esta Magistratura, la proporcionalidad del medio empleado para lograr la consecución del interés público legítimo exige evitar daños innecesarios (STC 1141/2009, c. 19²). En el campo del derecho de propiedad, esta Magistratura ha señalado que el medio empleado por el legislador es proporcionado en tanto no imponga al dueño sino una obligación indispensable para servir el interés público comprometido, en la medida que no existan otras alternativas disponibles, se evite causar daños innecesarios a los afectados y se cuente con la posibilidad de reclamar ante los Tribunales Ordinarios de Justicia (STC 1215/2008, c. 280)”.

${ }^{86}$ MolinerA, cit. (n. 80), p. 69: "OCTOGESIMO CUARTO: Que, por último, la jurisprudencia de esta Magistratura ha sostenido que la limitación impuesta al propietario debe ser mesurada y razonable (SSTC 56/1988, c. 12; 1863/2012, c. 51, y otras: 1986/2012, 1991/2012, 1992/2012, 1993/2012). El carácter mesurado y razonable de las limitaciones y obligaciones impuestas por los articulos 62, inciso segundo, y 160 de la LGUC puede vincularse a lo expuesto en los considerandos anteriores. Estas notas quedan ratificadas por la aplicación que han recibido las normas impugnadas de acuerdo con los antecedentes aportados en esta causa".

${ }^{87}$ Molinera, cit. (n. 80), p. 47; Mirow, Matthew C., Origins of the Social Function of Property in Chile, en Florida International University Legal Studies Research Paper Series 11-12 (2011), pp. 14 y 18. Mirow es citado en considerando sexagésimo.

${ }^{88}$ Molinera, cit. (n. 80), pp. 46 y 49. Rodríguez, Pedro Jesús, La propiedad privada, en Revista de Derecho y Jurisprudencia, tomo LXIX, enero-abril 1972, primera parte, p. 116, citado en considerando SEXAGESIMO y sexagésimo primero.

${ }^{89}$ Molinera, cit. (n. 80), p. 59. Bertelsen Repetto, Raúl, El Derecho de Propiedad en la Constitución de 1925, en Brahm García, Enrique, Propiedad sin libertad: Chile 1925-1973 (Santiago, Ediciones Universidad de los Andes, 1999), p. 47, citada en considerando septuagésimo segundo.

${ }^{90}$ Molinera, cit. (n. 80), p. 79: "Que, en lo concerniente al medio o reserva legal, la legislación urbanística, en general, ba estado bajo sospecha. Ya en la sentencia Rol No 370 este Tribunal afirmaba que la legislación urbanistica contiene disposiciones generales y enunciados muy amplios, en los cuales se confiere competencia a los órganos administrativos correspondientes, pero que, en ligamen con la reserva legal, precisa y vigorizada prevista en el artículo 19, $N^{o} 24^{\circ}$, inciso segundo, de la Constitución, para establecer las obligaciones del dominio que derivan de su función social, deben ser calificadas de inexistentes o, al menos, de insuficientes (STC Rol $N^{\circ} 370$, considerando 40')".

${ }^{91}$ Molinera, cit. (n. 80), p. 85: "Que, en efecto, la magnitud del menoscabo importa, de acuerdo a las sentencias de este Tribunal en los roles Nos 505 y 506, tal como se expresa a continuación: "Que la magnitud de la regulación no resulta entonces indiferente. Por una parte, porque toda regulación o limitación priva al propietario de algo. A partir de la regulación, alguna autonomía, privilegio, ventaja o libertad que tenía, desaparece para su titular. Si tuviéramos por 
Entre el voto de mayoría y minoría de los casos Molinera, la única coincidencia en las menciones de jurisprudencia se da en relación con el caso STC rol 370-2003. El voto de mayoría, que sostiene la idea de una propiedad diversificada y sometida a regulación, cita los considerandos 30 , 31, 34, 40 y 41 del caso STC rol 370-2003. En base a estos precedentes, argumenta que el artículo 19 número 24 de la Constitución habilita al legislador a regular el derecho de propiedad en nombre de la función social, y que esta habilitación se extiende a la potestad reglamentaria, siempre que se ejerza cuidando que no consista en meros "enunciados normativos", "disposiciones abiertas" y "normas carentes de determinación y especificidad".

El voto de minoría, en cambio, en su referencia del mismo caso STC rol 370-2001, se limita a mencionar el considerando 40 para afirmar que: "la legislación urbanistica, en general, ha estado bajo sospecha. Ya en la sentencia Rol No 370 este Tribunal afirmaba que la legislación urbanistica contiene disposiciones generales y enunciados muy amplios, en los cuales se confiere competencia a los órganos administrativos correspondientes, pero que, en ligamen con la reserva legal, precisa y vigorizada prevista en el artículo 19, $N^{\circ} 24^{\circ}$, inciso segundo, de la Constitución, para establecer las obligaciones del dominio que derivan de su función social, deben ser calificadas de inexistentes $o$, al menos, de insuficientes" 92 . Se trata, entonces, al igual que en el caso Santa Beatriz, de visiones bien distintas del mismo caso que se expresan en los casos Molinera.

\section{El caso Curtidos}

En tercer lugar, en el caso de Curtidos, al igual que en los casos Molinera, la cuestión jurídica se refiere a la petición de que se declare inaplicable por inconstitucional el artículo 62 de la Ley de Urbanismo y Construcción, que autoriza decretar el traslado de una empresa.

El voto de mayoría del caso Curtidos cita una serie de fallos que justifica el asumir una concepción unificada y reforzada, y que impone requisitos estrictos sobre la reglamentación que puede afectar la propiedad constitucional en la jurisprudencia del TC. Entre éstos, se citan los casos STC roles

propiedad cada aspecto de esa autonomía, privilegio, ventaja o libertad, la regla constitucional que permite limitar la propiedad equivaldría a letra muerta. (...) Por el contrario, legitimar cualquiera regulación o limitación, sin considerar su impacto sobre la propiedad, desnaturalizaría la protección de este derecho fundamental ("la limitación tiene sus límites", para usar una expresión ya clásica del derecho anglosajón). El carácter esencial de lo privado en virtud de la regulación es un parámetro siempre útil para hacer la distinción y debe utilizarse, aunque se determine que, prima facie, se trata de una regulación." (Considerando 23\%)".

${ }^{92}$ Molinera, cit. (n. 80), p. 79. 
$577-2006^{93}, 198-1994^{94}, 334-2001^{95}, 370-2003^{96}, 389-2003$ y $433-2005^{97}, y$ agrega sobre la esencia del derecho los casos STC roles 29-85, 185-1994, 245-1996 y 246-199698, junto con las referencias copulativas de los casos

${ }^{93}$ Fallo disponible [en línea]: http://www.tribunalconstitucional.cl/expediente file:///C:/Users/pruiztagle/Downloads/53254.pdf (consultado por última vez el 28 de febrero de 2018) en adelante denominado CuRTidos, p. 15: 'DECIMO... mientras no se aprueben las normas de calidad ambiental respectivas que determinen objetivamente los parámetros dentro de los cuales es admisible en el ambiente una sustancia o elemento, no corresponde hablar de contaminación, a menos que se acredite inequivocamente la presencia en el ambiente de un contaminante, en términos tales que constituya un riesgo cierto a la vida, a la salud de la población, a la conservación del ambiente o la preservación de la naturaleza, o bien que exista una situación de pública e indiscutida notoriedad de la presencia gravemente nociva en el ambiente de un contaminante" (Rol 577-2006 considerando 13\%)".

${ }^{94}$ CuRTIDOS, cit. (n. 93), p. 19: "DECIMO OCTAVO: Que lo anterior concuerda con la jurisprudencia de este Tribunal, donde se ha reprobado aquellas leyes que dejan abandonado el goce efectivo de los derechos y libertades a los poderes absolutamente discrecionales que pueda acometer, indeterminadamente, un órgano de la Administración, máxime cuando los motivos que autorizan su actuación sólo dependen de la apreciación libre y subjetiva de los agentes o funcionarios que participan en su aplicación (Rol $N^{\circ} 198$, considerando 10)".

${ }^{95}$ CurTidos, cit. (n. 93), pp. 21-22: "VIGESIMO SEGUNDO:... en la especie toma forma una supresión virtual de las prerrogativas inherentes al dominio, en circunstancias que la Constitución (articulo 19, $\mathrm{N}^{\circ} 24^{\circ}$, inciso tercero), a los efectos de exigir que medie una expropiación, entiende que la privación del dominio no sólo acontece cuando se quita o despoja al dueño de lo suyo, en su totalidad, sino también cuando al titular-aun conservando nominativamente tal carácter- se le desposee, parcialmente, de alguno de los atributos o facultades esenciales que caracterizan la propiedad, según ha señalado este Tribunal (Rol $N^{\circ} 334$, considerando 19०)".

${ }^{96}$ CurTIDOS, cit. (n. 93), p. 20: "DECIMO OCT AVO: ... las afectaciones al dominio, autorizadas por el artículo 19, $\mathrm{N}^{\circ} 24^{\circ}$, de la Constitución, están reservadas con vigor especial e ineludible al legislador, a quien le corresponde normar, con amplitud y profundidad, todo cuanto la certeza o seguridad jurídica exige en relación con el establecimiento y configuración de las obligaciones que se pueden imponer al ejercicio de tal derecho (Rol $N^{\circ} 370$, considerando 34)."

${ }^{97}$ CurTIDOs, cit. (n. 93), p. 21: "DECIMO OCTAVO: ... La ley es inconstitucional ha recalcado- cuando amaga o desampara aquellos derechos pasibles de restricciones a consecuencia de habilitaciones inespecificas conferidas a la autoridad, sin trazar esa ley las pautas o parámetros objetivos y controlables que garanticen que el órgano gubernamental se ha circunscrito a ellos, asumiendo la consecuente responsabilidad cuando los ba transgredido $\left(\mathrm{Rol} \mathrm{N}^{\circ} 389\right.$, considerando $25^{\circ}$, doctrina posteriormente aplicada en (Rol $N^{\circ} 433$, considerandos $30^{\circ}, 31^{\circ}$ y $\left.34^{\circ}\right)$ ".

${ }^{98}$ CuRTIDOS, cit. (n. 93), p. 23: "VIGESIMO QUINTO: Que el acto regulatorio difiere de una limitación en su contenido y alcance. El primero es aquel que tiene por objeto determinar las reglas conforme a las cuales se debe usar, gozar y/o disponer de la propiedad, orientadas precisamente a resguardar su ejercicio efectivo e impedir que se emplee contra la ley o contra derecho ajeno. Como se sabe, después del terremoto ocurrido en Talca el año 1928, con este objetivo se dictó la Ley $N^{\circ} 4.563$, que luego daría origen a la primera Ley General sobre Construcciones y Urbanización, con el DFL $N^{\circ} 345$, de 1931. El objeto de la limitación, en cambio, consiste en restringir, acortar o ceñir, reduciendo a menores limites, la extensión donde puede ejercerse el derecho, pero dejando plenamente vigentes sus facultades esenciales, según precisa la jurisprudencia 
STC roles 226-1995, 280-1998, 293-1999, 325-2001 y 1365-200999. Si

(roles $N^{\circ}$ s 29, 185, 245, 246, entre otros)". Así al revisar respectivamente el caso STC rol 29-1985 que fue resuelto el 7 de junio de 1985 se observa que se no contiene menciones directas a las normas sobre el derecho de propiedad y se vincula con la idea de las limitaciones que pueden imponerse a los derecho en el contexto del debate sobre la constitucionalidad del proyecto de ley orgánica constitucional de los estados de excepción; el caso STC rol 185-1994 se refiere al control de constitucionalidad de la Ley sobre Medio Ambiente resuelto el 28 de febrero 1994 y contiene un concepto reforzado de propiedad en el número 12 letra c; y el caso STC rol 245-1996 resuelto el 2 de diciembre 1996 se refiere a un requerimiento contra un decreto supremo que impone acceso a playas por terrenos colindantes y en sus números 6 a 11 se citan normas sobre playas y propiedad del Código Civil, en el número 12 se cita el artículo 19 número 23 de la Constitución en relación con el acceso a la propiedad y desde el número 21 hasta el 30 inclusive de los considerandos se tratan las limitaciones que la Constitución admite respecto de la propiedad en base a la función social entre otras razones para concluir por voto de mayoría que es inconstitucional el decreto impugnado en base a un concepto reforzado de propiedad; y finalmente, el caso STC rol 246-1996 resuelto con fecha 2 de diciembre de 1996 en sus considerandos 6 a 11 inclusive refiere normas del Código Civil y a partir del considerando 12 y hasta el considerando 34 se refiere al artículo 19 número 23 y al artículo 19 número 24 con una concepción de propiedad unificada y reforzada y que impone requisitos estrictos sobre la reglamentación que puede afectar la propiedad que sirve para declarar por voto de mayoría el decreto impugnado en término semejantes al caso 245-1996.

${ }^{99}$ CuRTIDOS, cit. (n. 93), p. 24. "VIGESIMO SÉPTIMO: Que, en todo caso, aun de admitirse que en la especie se trataría de una mera restricción al dominio, es lo cierto que la jurisprudencia de esta Magistratura ha advertido que todas las limitaciones al ejercicio de los derechos deben poseer determinación y especificidad; no pueden afectar la esencia del derecho asegurado y, además, han de respetar el principio de igualdad, especialmente en cuanto deben estar establecidas con parámetros incuestionables. Esto es, que deben ser razonables y justificadas, de donde se sigue que han de ser mesuradas, necesarias y proporcionadas (roles $N^{\circ}$ s 226, 280, 293, 325 y 1.365). El caso STC rol 226-1995 fue resuelto el 30 de octubre de 1995 y es un requerimiento contra las normas de la Ley de Libertad de Expresión que imponen un derecho a la información, aclaración y rectificación y en los considerandos 46 a 53 inclusive del fallo se argumenta en base a la concepción de propiedad es unificada y reforzada y que impone requisitos estrictos sobre la reglamentación que puede afectar la propiedad la declaración de inconstitucionalidad de la norma del proyecto que ha sido objeto del requerimiento. Por su parte, el caso STC rol 280-1998 dictado el 20 de octubre 1998 es un requerimiento sobre un proyecto de ley que rebaja aranceles y aumenta los tributos al tabaco y los combustibles y en el considerando 13 y luego con más detalle a partir del considerando 28 y hasta el 33 inclusive se trata en detalle el tema del contenido esencial del derecho para fundar el rechazo del requerimiento; el caso STC rol 293-1999 que controla la constitucionalidad de la ley orgánica del Ministerio Público donde no se han encontrado referencias a materias vinculadas al derecho de propiedad; el caso STC rol 325-2001 fallado el 26 de junio 2001 que se refiere a un requerimiento contra una restricción medio ambiental y el tribunal en 35 considerandos discurre sobre cuestiones de forma y a partir del considerando 39 se 
uno revisa las sentencias del TC citados por el voto de mayoría en el caso Curtidos, se concluye que ellos se remontan a una concepción de propiedad que es unificada y reforzada, y que impone requisitos estrictos sobre la reglamentación que puede afectar la propiedad, vinculada con normas del Código Civil (ver casos STC rol 245-1996 y 246-1996) y/o, alternativamente, se construye en torno a las propias normas constitucionales, sin referencia al Código (ver caso STC rol 185-1994).

En cambio, el voto de minoría en el caso Curtidos está fundado en una concepción diversificada y sometida a regulación de la propiedad, por lo que su argumentación gira en primer término en torno a las características especiales de la propiedad urbana. Para ello, cita los precedentes de los

argumenta acerca del conflicto entre la propiedad y la libertad ambulatoria versus el medio ambiente para dictaminar que se rechaza por mayoría el requerimiento; el caso STC rol 325-2001 de 26 de junio 2001 que también tiene 35 considerandos sobre cuestiones de forma y en cuanto al fondo, el considerando 39 y hasta el 47 discurre sobre la propiedad y la libertad ambulatoria en relación con el medio ambiente para rechazar por mayoría el requerimiento y admitir limitaciones impuestas para evitar la contaminación; finalmente, el caso STC rol 1365-2009 fallado el 8 de abril 2010 sobre inaplicabilidad de norma que impone obligación de obtener huella biológica en registro de $\mathrm{ADN}$ de condenados se debate a partir del considerando trigésimo sexto y hasta el considerando cuadragésimo primero la afectación del contenido esencial del derecho fundamental a la igualdad y la integridad física y psíquica para justificar el rechazo de la inaplicabilidad. 
casos STC roles 2643-2015 y 2644-2015 ${ }^{100}$, 2264-2012 101 y 253-1997102. También cita los fallos sobre la faja de un camino público, en los casos STC roles 1863-2012, 1986-2012, 1991-2012, 1992-2012 y 1993$2013^{103}$. Cita, adicionalmente, fallos para justificar el argumento de que la propiedad se encuentra sujeta a requerimientos colectivos por efecto de la función social, en los casos STC roles 245-96 y 2299-12 ${ }^{104}$. Para jus-

${ }^{100}$ Curtidos cit. (n.55), p.34. Los casos 2643-2015 y 2244-2015 son los casos denominados Molinera que en el voto de minoría se citan en los considerandos 5 a 7 inclusive para argumentar que en el caso CuRTIDos se cumplen todos los requisitos de aplicación del artículo 62 porque la industria está mal ubicada según el plan regulador y que ocasiona molestias y perturbación en la vida, salud y propiedad de las personas que gatilla el proceso resolutivo y sancionatorio de la Municipalidad en conjunto con el Ministerio de Vivienda y el Ministerio de Salud. Es un recuerdo del voto de minoría de dos casos anteriores que se resolvieron con un criterio contrario al que sustenta el voto de mayoría en Curtidos. La forma más directa de sintetizar el vínculo que existe entre los casos de Molinera al caso Curtidos se da en CuRTidos cit. (n.55), p.34 que tiene la siguiente afirmación en el voto de minoría: Uno de esos estatutos es la propiedad urbana. En ella se compatibilizan los intereses públicos con la protección de Los derechos privados, con el fin de armonizar cuatro necesidades vitales: habitar, trabajar, recrearse $y$ circular (STC 2643/2015 y 2644/2015).

${ }^{101}$ CuRTIDOs cit. (n.55), p.31. 10. Que, por otra parte, la medida que puede disponer la autoridad es el traslado. Se trata de una orden. Como ba dicho esta Magistratura, la orden es una técnica de intervención de la Administración en la actividad económica, mediante la cual se crean o imponen deberes u obligaciones. Esta genera un mandato imperativo de realizar una determinada conducta a través de la cual la Administración concreta una obligación para un particular. En la orden la Administración, previa babilitación legal, concreta un deber para una situación particular, enunciado de modo general en la ley. Por eso se dice que la orden es constitutiva, pues define quién, cómo, cuándo, dónde se debe cumplir un mandato determinado. La orden hace surgir en sus destinatarios un deber de obediencia, de conformar la propia conducta a lo establecido en ella. La orden puede serpositiva, de realizar una determinada conducta, o puede ser un mandato omisivo, es decir, genera una probibición (STC 2264/2012).

${ }^{102}$ CURTIDOs cit. (n.55), p.32. 12. Que, en primer lugar, en la STC 253/1997 el Tribunal consideró ajustado a la Constitución que el urbanizador debia entregar gratuitamente un porcentaje del terreno que urbanizaba para áreas verdes y equipamiento comunitario. El Tribunal consideró que con ello se evitaba el deterioro de las comunidades vecinas para lograr el desarrollo armónico y equitativo de las ciudades. La norma, dijo, concilia en forma prudente y justa los intereses personales del urbanizador con los de la sociedad toda;

103 13. Que, en segundo lugar, este Tribunal consideró legítimo que se dispusiera el traslado de redes de empresas de servicio público ubicadas en la faja de un camino público, pues ello se funda en el beneficio que para la sociedad toda trae consigo el mejoramiento de dichos caminos, garantizando de esa forma la libertad ambulatoria que la Constitución establece (STC 1863/2012, 1986/2012, 1991/2012, 1992/2012, 1993/2012);

104 34. Que las limitaciones al dominio se fundan en la función social de la propiedad. Esto significa que hay un valor individual y social en el dominio. Por lo mismo, debe estar al servicio de la persona y de la sociedad. Implica que dejan de ser lo mismo los intereses privados de la propiedad con los intereses sociales. La propiedad privada queda, por efecto de la función social, 
tificar su concepción limitada de la propiedad, cita los casos sobre franja de televisión STC roles 56-1988 y 2487-2013 ${ }^{105}$. Todas estas sentencias tratan sobre potestades de la administración, pero también sobre cuestiones sustantivas referidas a la propiedad urbana, por las que se agregan al considerando 18 del voto de minoría la afirmación más directa sobre los diversos tipos de propiedad que admite la Constitución. En abono de su postura, refiere los casos STC roles 807-2000, 1298-2009, 2643-2015 $5^{106}$. Agrega además, sobre regulación de la propiedad y separación de poderes, los casos STC rol 325-2001, 370-2003 y 480-2006 ${ }^{107}$. Sobre la potestad del TC de control de atribución y no de ejercicio o mérito de las normas, se cita en el considerando 21 el caso STC rol 2069-2011 ${ }^{108}$.

En el caso Curtidos encontramos que, en el voto de mayoría, el conflicto entre la salud y la propiedad no está bien tratado, porque la salud no es una cuestión enteramente subjetiva, sino que tiene que ver con estándares que impone la autoridad, que en este caso se cumplieron en toda su extensión. Además, en la opinión mayoritaria está la idea de que la limitación debe ser determinada y específica, que sirve para impugnar la medida de traslado fundada en el artículo 62 de la Ley de Urbanismo y Construcción, pero

sujeta a requerimientos colectivos (STC 245/1996, 1863/2012, 1986/2012, 1991/2012, 1992/2012, 1993/2012 y 2299/2012);

${ }^{105}$ CuRTIDOs cit. (n.55), p.33. 14. Que, en tercer lugar, este Tribunal validó también el que los canales de televisión de libre recepción estuvieran sujetos a una franja televisiva obligatoria y gratuita, como justa contrapartida del derecho monopólico que se les otorga y del interés general de la colectividad involucrado en las elecciones (STC 56/1988, 2487/2013)

${ }^{106}$ CURTIDOs cit. (n.55), p.33-34. 18. Que, en primer lugar, la Constitución no establece un modelo único de propiedad, al cual deban ceñirse el resto de las propiedades. El constituyente se mantiene neutro frente a las preferencias constitutivas del legislador al momento de definir el modo en que se ha de adquirir, usar, gozar y disponer de una propiedad, y las limitaciones y obligaciones que deriven de su función social. La Constitución asegura la propiedad en sus diversas especies (STC 807/2000, 1298/2009, 2643/2015 y 2644/2015).

${ }^{107}$ CuRTIDOS, cit. (n. 93), p. 35: "20. Que el segundo criterio interpretativo dice relación con el equilibrio que existe entre la ley y el reglamento. Esta Magistratura ha sostenido que es posible y lícito que las normas administrativas puedan regular (STC 325/2001). La Constitución diseña un régimen que armoniza potestad legislativa con la potestad reglamentaria (STC 370/2003). Afirmar que una determinada materia está regida por el principio de legalidad, no equivale a excluir la potestad reglamentaria, dada la interpretación armónica que debe existir entre los articulos 63 y 32, $N^{\circ}$ 6, por la naturaleza general y abstracta de la ley y por la división de funciones entre el Legislativo y el Ejecutivo (STC 480/2006)".

${ }^{108}$ CurTidos, cit. (n. 93), p. 36: "21. Que, en tercer lugar, este Tribunal realiza en la acción de inaplicabilidad un control de atribución de potestades, no de ejercicio de las mismas. En virtud del primero, se controla la entrega de atribuciones a la Administración. Mediante el segundo, se examina la dictación de los actos que se emiten en virtud de la potestad otorgada (STC 2069/2012)". 
que no considera todos los informes previos en que se funda la decisión municipal del caso Curtidos, tales como el proceso de cambio de plan regulatorio, los informes de las autoridades de salud y los informes del Ministerio de Vivienda, entre otros. Se objeta la decisión como si se tratara de una decisión francamente caprichosa del alcalde, cuestión que no es efectiva. Así, en el caso de Curtidos se ha impuesto a nivel constitucional un concepto de la propiedad que el TC no ha delimitado en sus contornos, y que merece ser criticada en sus fundamentos y justificación.

\section{Visión de conjunto}

Entre las críticas que ha generado esta jurisprudencia del TC, se ha llegado a sostener que esta concepción de la propiedad unificada y reforzada, y que impone requisitos estrictos sobre la reglamentación, tendría un carácter pre-político y que no sería democrática ${ }^{109}$. Esta argumentación se ha fundado en un estudio de la jurisprudencia del TC en los casos sobre requerimientos de la Ley de Prensa (caso STC rol 226), de la Ley de Rentas Vitalicias (caso STC rol 334), de la Ley sobre Subcontratación (caso STC rol 410 y STC rol número 534-2006). Sin embargo, al revisar esta crítica, se concluye que no parece bien fundada ${ }^{110}$. De partida, no considera que la propiedad constitucional hunde sus raíces en ideas republicanas que imponen un límite al poder de las mayorías, y no por eso ha de ser considerada como necesariamente contraria a la democracia constitucional ${ }^{111}$. Una crítica mejor fundada a esta jurisprudencia ha sido expuesta por Matías Guiloff, quien analiza el concepto de discrecionalidad administrativa que expone el voto de mayoría en los casos Molinera y el caso Curtidos $^{112}$. La crítica del Profesor Guiloff incluye referencias al tema de la propiedad, pero éstas son de carácter más bien general, porque el foco de su trabajo es la crítica a la exigencia de precisión y determinación en la regulación de la propiedad.

Para tener una mejor visión de conjunto acerca de las concepciones que fundan esta jurisprudencia, en las líneas que siguen se agregan algunas

\footnotetext{
${ }^{109}$ Cortés, P. - García, G. - Torres, P., Hacia una lectura democrática del derecho de propiedad en la Constitución chilena, en Derecho y Crítica Social 1 (2015), 2, pp. 332-333.

${ }^{110}$ Cortés, P. - García, G. - Torres, P., cit. (n. 109), pp. 339-353.

${ }^{111}$ Ruzz-Tagle, Pablo, La propiedad en el constitucionalismo republicano y su aplicación al Chile actual, en Cristi, Renato - Ruiz-TAgLe, Pablo, El Constitucionalismo del miedo. Propiedad, bien comun y poder constituyente (Santiago, Editorial LOM, 2014), pp. 31-71.

${ }^{112}$ GuILOFF, Matías, Elija cual derecho de propiedad privada se protege: la precisión de las normas legales que establecen limitaciones a la propiedad privada a propósito de los fallos Molinera del Norte y Curtidos Bas, en Anuario de Derecho Público (Santiago, Ediciones Universidad Diego Portales, 2016), pp.152-167.
} 
ideas adicionales sobre la concepción de la propiedad constitucional que surge de los casos Santa Beatriz, Molinera y Curtidos, en el entendido que a partir de ellos ha surgido en Chile un verdadero dilema.

Si se revisa la tabla resumen que se contiene en esta sección, puede concluirse que los Ministros del TC, no sólo están en desacuerdo sobre la interpretación de sus propios precedentes y acerca del sentido de los considerandos a partir de los cuales se puede construir su argumentación jurídica, sino que además eligen con gran discrecionalidad sus casos para ciertos y determinados periodos del TC. Los Ministros del TC que tienen una concepción de la propiedad diferenciada y flexible, que admite diversas formas de reglamentación, citan casos de varios periodos, pero generalmente mencionan casos fallados con posterioridad a 2009. Los Ministros del TC que tienen la concepción de propiedad unificada y reforzada, y que impone requisitos estrictos sobre la reglamentación que puede afectar la propiedad, argumentan su posición en torno a precedentes anteriores al año 2009. Incluso citan y asignan valor a sentencias de casos antiguos del periodo pre-constitucional, esto es, anteriores al mes de marzo de 1990, fecha en que se retorna a la democracia en Chile.

5. Tabla resumen de referencias con precedentes sobre jurisprudencia sobre propiedad en sentencias casos TC

\begin{tabular}{|c|c|c|}
\hline Caso & Referencias Voto de Mayoría & Referencias Voto de Minoría \\
\hline $\begin{array}{l}\text { Santa Beatriz. } \\
\text { (Enero 2014) }\end{array}$ & $\begin{array}{l}245-996 \text { y } 246-1996,943-2007, \\
1309-2009,1215-2008 \text { y } 325- \\
2001\end{array}$ & $\begin{array}{l}19-1983 \text { y } 1185-2008,325- \\
2001,1185-2008,370-2003, \\
226-1996,198-1994,339-2001 \\
\text { y } 433-2005\end{array}$ \\
\hline $\begin{array}{l}\text { Molinera } \\
\text { (Enero 2015) }\end{array}$ & $\begin{array}{l}370-2003,1298-2009,334- \\
\text { 2001, 1295-2008, 1215-2008, } \\
\text { 1182-2008, 1193-2003, 1201- } \\
\text { 2008, 1541-2009, 1141-2008, } \\
\text { 56-1988, 1863-2012, 1986- } \\
2012,1991-2012 \text { у 1993-2012 }\end{array}$ & $\begin{array}{l}370-2003 \text { y } 505-2006 \text { y } \\
506-2006\end{array}$ \\
\hline $\begin{array}{l}\text { Curtidos } \\
\text { (Septiembre } \\
2015 \text { ) }\end{array}$ & $\begin{array}{l}\text { 577-2006, 198-1994, } \\
334-2001,370-2003, \\
389-2003 \text { y 433-2005, } \\
29-1985,185-1994,245- \\
1996,246-1996,226- \\
1995,280-1998,293-999, \\
325-2001 \text { у 1365-2009, } \\
505-2006\end{array}$ & $\begin{array}{l}\text { 2643-2015, 2644- } \\
\text { 2015, 2264-2012, 253- } \\
\text { 1997,1863-2012; 1986- } \\
\text { 2012, 1991-2012; 1992- } \\
\text { 2012; 1993-2013, 56-1988, } \\
\text { 2487-2013, 807-2000; } \\
\text { 1298-2009; 2643-2015, } \\
325-2001,370-2003,480- \\
2006,2069-2011\end{array}$ \\
\hline
\end{tabular}


Además, en la observación de la tabla resumen anterior, se aprecia cómo ni en el caso Santa Beatriz, ni en los casos Molinera, ni en el caso Curtidos, el voto de mayoría parece intercambiar argumentos con el de minoría, porque, salvo un par de excepciones, cada una de ellas se funda en sus propios precedentes. Cada una de estas opiniones se concibe como una sentencia separada. Esto da pie para que podamos sostener que en la jurisprudencia del TC chileno hay un dilema, un istmo en su concepción de propiedad.

Siempre pueden darse discrepancias en las decisiones del TC. En todos los Tribunales Constitucionales del mundo existen disensos y pasan por varias etapas para darle estabilidad a sus resoluciones. El problema es que en Chile estos disensos a nivel constitucional no generan un diálogo abierto entre las posiciones que son adversarias. Así, tenemos un TC que está quebrado en su propia jurisprudencia en un dilema en torno a la concepción de la propiedad que no respeta la regla de los precedentes, porque no se hace cargo de razonar en torno a argumentos compartidos en sus fallos, sino que elige sus precedentes sin justificarlos. Porque, como se muestra en los casos Santa Beatriz, Molinera y Curtidos, la jurisprudencia sobre propiedad del TC se construye con discrecionalidad, y atribuye significado a los casos que sólo reproducen la sección de la sentencia que más se aviene a sus convicciones.

\section{CONCLUSIÓN}

A partir de lo expuesto, nuestra conclusión es que existe suficiente evidencia para afirmar que la propiedad privada a nivel constitucional en Chile no tiene un concepto único, sino que tiene forma de dilemas y carácter multiforme. De esta manera, estimamos que la hipótesis planteada en la Introducción de este trabajo es comprobada y no refutada por el material normativo asociado a la costumbre, la doctrina y la jurisprudencia como fuentes del Derecho Constitucional chileno.

Adicionalmente, podemos señalar que en Chile hoy existe una serie de dilemas de orden doctrinario sobre la propiedad en el derecho privado y/o público, y que inciden sobre su comprensión y aplicación. Existe también un conjunto de dilemas jurisprudenciales vinculados a decisiones sobre la propiedad, particularmente del Tribunal Constitucional chileno, basadas en al menos dos concepciones de la propiedad. Una es diferenciada y flexible y admite diversas formas de su reglamentación, y la otra es una concepción que percibe la propiedad como unificada y reforzada y 
que impone requisitos estrictos a la reglamentación que puede afectarla. Estos dilemas doctrinarios y jurisprudenciales también contrastan con las concepciones ciudadanas de la propiedad que recientemente se han expresado en los encuentros locales auto convocados en que el gobierno invitó a participar el año 2017. Estas ideas ciudadanas coinciden en parte con la doctrina y jurisprudencia chilena, pero al mismo tiempo agregan elementos nuevos, tales como la idea de vincular el derecho de propiedad con el derecho a la vivienda, con la idea de asegurar un mínimo de propiedad a todas las personas, o con la idea de proteger la propiedad indígena a nivel constitucional. Todos estos dilemas de la propiedad constituyen verdaderos desafíos que debemos considerar al momento de considerar el análisis y la organización del derecho de propiedad en Chile.

\section{BiBLIOGRAFÍA}

Ackerman, Bruce, Private Property and the Constitution (New Haven and London, Yale University Press, 1977).

Aldunate Lizana, Eduardo, Derechos Fundamentales (Santiago, LegalPublishing, 2008).

Amunátegur Perello, Carlos Felipe, Hacia un concepto de inmisiones en el derecho chileno, en Revista Chilena de Derecho 40 (2013), 1.

BRAHM, Enrique, La perversión de la cultura chilena durante el gobierno de la Unidad Popular. "resquicios legales" y derecho de propiedad, en Revista Chilena de Historia del Derecho 18 (1999-2000).

Bustos, Rodrigo, Función social y limites del derecho de propiedad. Temas emergentes en el derecho internacional de los derechos humanos, en Estudios de Derecho Privado. Libro en homenaje al profesor Gonzalo Figueroa Yáñez (Santiago, Editorial Jurídica de Chile, 2008).

Carrasco Albano, Manuel, Comentarios a la Constitución Politica de 1833 (2º edición, Santiago, Imprenta de la librería del Mercurio, Colección Obras de Derecho Público, Tribunal Constitucional de Chile, 2016), I.

Cordero Quinzacara, Eduardo, La dogmática constitucional de la propiedad en el derecho chileno, en Revista de Derecho de la Universidad Austral de Chile 29 (2006).

Corral, Hernán, Propiedad y cosas incorporales. Comentarios a propósito de una reciente obra del profesor Alejandro Guzmán Brito, en Revista Chilena de Derecho 23 (1996), 11.

Cordero Quinzacara, Eduardo - Aldunate lizana, Eduardo, Evolución histórica del concepto de propiedad, en Revista de Estudios Histórico-Jurídicos de la Pontificia Universidad Católica de Valparaíso 30 (2008).

Cortés, P. - García, G. - Torres, P., Hacia una lectura democrática del derecho de propiedad en la Constitución chilena, en Derecho y Crítica Social 1 (2015), 2.

Cristi, Renato - Ruiz-Tagle, Pablo, La República en Chile. Teoría y práctica del Constitucionalismo Republicano (Santiago, LOM Ediciones, 2006). 
Cristi, Renato - Ruiz-Tagle, Pablo, La República en Chile: Teoría y práctica del constitucionalismo republicano (2o edición, Santiago, LOM Ediciones, 2008).

Cristi, Renato - Ruiz-Tagle, Pablo, El Constitucionalismo del miedo. Propiedad, bien común y poder constituyente (Santiago, Editorial LOM Ediciones, 2014).

Ely, J. W., The guardian of every other right. A constitutional history of property rights (New York, Oxford, Oxford University Press, 2008).

Evans, Enrique, Los derechos constitucionales (Santiago, Editorial Jurídica de Chile, 1999), III.

Guiloff, Matías, Elija cual derecho de propiedad privada se protege: la precisión de las normas legales que establecen limitaciones a la propiedad privada a propósito de los fallos Molinera del Norte y Curtidos Bas, en Anuario de Derecho Público UDP (Santiago, Ediciones Universidad Diego Portales, 2016).

GuZMÁn, Alejandro, Las cosas incorporales en la doctrina y en el derecho positivo (Santiago, Editorial Jurídica de Chile, 1995).

Huneeus, Jorge, La Constitución ante el Congreso (2o edición, Santiago, Imprenta Cervantes, 1890, Colección Obras de Derecho Público, Tribunal Constitucional de Chile, 2016), II.

Peñailillo, Daniel, Los Bienes (Santiago, Editorial Jurídica de Chile, 2006).

Real Academia Española, Diccionario (20 tercera edición, Madrid, Real Academia Española, 2014).

Ríos, Lautaro, El principio constitucional de la función social de la propiedad, en Revista de Derecho y Jurisprudencia (Santiago, Edición Bicentenario, Derecho Civil, Bienes, Thomson Reuters, 2010).

Rose, Carol, Property as Storytelling: Perspectives from game theory, narrative theory, feminist theory, en Yale Journal of Law and Humanities 2 (1990).

Ruiz-Tagle Vial, Pablo, Propiedad Intelectualy Contratos (Santiago, Editorial Jurídica de Chile, 2001).

Ruiz-TAgle, Pablo, La propiedad en el constitucionalismo republicano y su aplicación al Chile actual, en Cristi, Renato - Ruiz-Tagle, Pablo, El Constitucionalismo del miedo. Propiedad, bien común y poder constituyente (Santiago, Editorial LOM, 2014).

Ruiz-Tagle Vial, Pablo, Cinco Repúblicas y una tradición. Constitucionalismo chileno comparado, (Santiago, LOM Ediciones, Colección Derecho en Democracia, 2016).

Soto, Francisco - Welp, Janina, Los "diálogos" ciudadanos. Chile ante el giro deliberativo (Santiago, LOM Ediciones, 2017).

UnderkufFler, Laura, The idea of Property: Its meaning and power (Oxford, Oxford University Press, 2003).

Valencia Avaria, Luis, Anales de la República (Santiago, Imprenta Universitaria, 1951), I.

Vergara Blanco, A., La propietarización de los derechos, en Revista de Derecho de la Pontificia Universidad Católica de Valparaíso 14 (1991). 